NASA/TM-2006-214372

\title{
Apollo Seals: A Basis for the Crew Exploration Vehicle Seals
}

Joshua R. Finkbeiner, Patrick H. Dunlap, Jr., and Bruce M. Steinetz

Glenn Research Center, Cleveland, Ohio

Christopher C. Daniels

University of Akron, Akron, Ohio 


\section{NASA STI Program . . . in Profile}

Since its founding, NASA has been dedicated to the advancement of aeronautics and space science. The NASA Scientific and Technical Information (STI) program plays a key part in helping NASA maintain this important role.

The NASA STI Program operates under the auspices of the Agency Chief Information Officer. It collects, organizes, provides for archiving, and disseminates NASA's STI. The NASA STI program provides access to the NASA Aeronautics and Space Database and its public interface, the NASA Technical Reports Server, thus providing one of the largest collections of aeronautical and space science STI in the world. Results are published in both non-NASA channels and by NASA in the NASA STI Report Series, which includes the following report types:

- TECHNICAL PUBLICATION. Reports of completed research or a major significant phase of research that present the results of NASA programs and include extensive data or theoretical analysis. Includes compilations of significant scientific and technical data and information deemed to be of continuing reference value. NASA counterpart of peer-reviewed formal professional papers but has less stringent limitations on manuscript length and extent of graphic presentations.

- TECHNICAL MEMORANDUM. Scientific and technical findings that are preliminary or of specialized interest, e.g., quick release reports, working papers, and bibliographies that contain minimal annotation. Does not contain extensive analysis.

- CONTRACTOR REPORT. Scientific and technical findings by NASA-sponsored contractors and grantees.
- CONFERENCE PUBLICATION. Collected papers from scientific and technical conferences, symposia, seminars, or other meetings sponsored or cosponsored by NASA.

- SPECIAL PUBLICATION. Scientific, technical, or historical information from NASA programs, projects, and missions, often concerned with subjects having substantial public interest.

- TECHNICAL TRANSLATION. Englishlanguage translations of foreign scientific and technical material pertinent to NASA's mission.

Specialized services also include creating custom thesauri, building customized databases, organizing and publishing research results.

For more information about the NASA STI program, see the following:

- Access the NASA STI program home page at http://www.sti.nasa.gov

- E-mail your question via the Internet to help@sti.nasa.gov

- Fax your question to the NASA STI Help Desk at 301-621-0134

- Telephone the NASA STI Help Desk at 301-621-0390

- Write to:

NASA STI Help Desk

NASA Center for AeroSpace Information 7121 Standard Drive Hanover, MD 21076-1320 
NASA/TM-2006-214372

AIAA-2006-5259

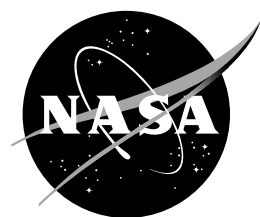

\section{Apollo Seals: A Basis for the Crew Exploration Vehicle Seals}

Joshua R. Finkbeiner, Patrick H. Dunlap, Jr., and Bruce M. Steinetz

Glenn Research Center, Cleveland, Ohio

Christopher C. Daniels

University of Akron, Akron, Ohio

Prepared for the

42nd Joint Propulsion Conference and Exhibit

cosponsored by the AIAA, ASME, SAE, and ASEE

Sacramento, California, July 9-12, 2006

National Aeronautics and

Space Administration

Glenn Research Center

Cleveland, Ohio 44135 
Trade names and trademarks are used in this report for identification only. Their usage does not constitute an official endorsement, either expressed or implied, by the National Aeronautics and Space Administration.

Level of Review: This material has been technically reviewed by technical management.

Available from

NASA Center for Aerospace Information 7121 Standard Drive

Hanover, MD 21076-1320
National Technical Information Service 5285 Port Royal Road Springfield, VA 22161

Available electronically at http://gltrs.grc.nasa.gov 


\title{
Apollo Seals: A Basis for the Crew Exploration Vehicle Seals
}

\author{
Joshua R. Finkbeiner, Patrick H. Dunlap, Jr., and Bruce M. Steinetz \\ National Aeronautics and Space Administration \\ Glenn Research Center \\ Cleveland, Ohio 44135 \\ Christopher C. Daniels \\ University of Akron \\ Akron, Ohio 44325
}

\begin{abstract}
The National Aeronautics and Space Administration is currently designing the Crew Exploration Vehicle (CEV) as a replacement for the Space Shuttle for manned missions to the International Space Station, as a command module for returning astronauts to the moon, and as an earth reentry vehicle for the final leg of manned missions to the moon and Mars. The CEV resembles a scaled-up version of the heritage Apollo vehicle; however, the CEV seal requirements are different than those from Apollo because of its different mission requirements. A review is presented of some of the seals used on the Apollo spacecraft for the gap between the heat shield and backshell and for penetrations through the heat shield, docking hatches, windows, and the capsule pressure hull.
\end{abstract}

\section{Introduction}

$\mathrm{T}$ he Crew Exploration Vehicle (CEV) is currently being designed by the National Aeronautics and Space Administration (NASA) as the United States' newest manned space vehicle to replace the Space Shuttle for missions to low earth orbit (LEO) and to enable long duration exploration missions to the moon and Mars. Several mission profiles envisioned for the CEV are described in Ref. 1. The CEV will carry as many as six astronauts to the International Space Station (ISS), where it will remain docked for up to six months to serve as a "lifeboat" escape capsule. At the end its mission, the CEV will return the crew to Earth while another CEV will carry a replacement crew to the ISS. The CEV will also carry four astronauts to lunar orbit where it will serve as a staging platform supporting manned excursions to the lunar surface. Eventually, the CEV may remain unmanned in lunar orbit for as long as six months while the astronauts reside in a permanent lunar surface base. The CEV is also envisioned to serve as an Earth reentry vehicle at the conclusion of a manned mission to Mars.

The CEV will require advanced seals to prevent the loss of habitable atmosphere to space. Long duration space missions must minimize the amount of crew cabin atmospheric leakage to ensure crew safety and to reduce the launch weight of additional oxygen to compensate for leakage. Missions to the moon or Mars will not be able to quickly return to Earth in case of excessive atmospheric losses, so the crew cabin pressure seals must be reliable for long mission durations.

The CEV will also require advanced thermal barriers and seals to ensure that high enthalpy reentry gases are not ingested into gaps where they could potentially cause damage to interior structures. At the conclusion of lunar exploration missions, the CEV will encounter the most severe reentry environment since the Apollo program. Atmospheric reentry at the conclusion of manned missions to Mars will generate temperatures exceeding those generated during lunar returns. The CEV will also enter the atmosphere from missions to LEO on a trajectory less severe than lunar reentries. However, the LEO reentry environment will still generate high thermal loads and heat fluxes on the vehicle thermal protection system (TPS).

Of the vehicles used by the United States in the history of manned spaceflight, the CEV compares best to the Apollo spacecraft in terms of mission profile, time in space, and reentry conditions, so the design of seals for the CEV may be initiated by examining seals used on the Apollo command module. This paper presents a review of seal technologies used on Apollo. As part of this review, the authors took several photographs of seals on the Apollo/Skylab 3 command module which was launched in 1973 and is currently on display in the Visitor Center at the NASA Glenn Research Center. Photographs from other command modules are also featured when these capsules are better suited to show particular details of specific seals. 


\section{Overview of Seals on the Apollo Command Module}

The Apollo command module required seals in several locations, including pressure seals to minimize the loss of cabin atmosphere while in space and thermal seals to prevent the influx of high enthalpy reentry gases through gaps in the TPS and into temperature-sensitive regions of the vehicle. To understand the seals used for Apollo, a description of the command module is first presented. Included in this discussion is a description of the TPS and the reentry environment to which the vehicle was exposed. Seals for penetrations through the heat shield, such as gaps between heat shield components and mechanisms for attaching the command module to the service module, are then discussed. Finally, pressure seals for penetrations into the crew cabin and their roles in retaining habitable atmosphere within the crew cabin are presented.

\section{A. Description of Apollo Command Module and the Reentry Environment}

The mission of the Apollo spacecraft was to carry three astronauts to lunar orbit, support a manned excursion to the lunar surface by two of the astronauts, and return the three astronauts safely to Earth. The Apollo capsule was also used for missions to LEO, initially for system testing in preparation for the lunar missions and later for missions to the Skylab space station and for the cooperative Apollo/Soyuz mission with the Soviet Union. The spacecraft was composed of two separate modules: the command module (CM) which housed the crew and served as a reentry vehicle for return to Earth and the service module (SM) which housed the SM propulsion system and provided logistics such as oxygen and electrical power. A third module, the lunar module (LM), was designed to carry two astronauts to the lunar surface and was used for Apollo missions starting with Apollo 9 and ending with Apollo 17 (a LM was also flown unmanned during Apollo 5). Figure 1 shows a schematic diagram of the Apollo command module, and Ref. 2 provides a general overview of the Apollo mission profile and the three modules of the Apollo spacecraft. Reference 3 used modern computer aided design (CAD) software to create a detailed engineering model of the Apollo command and service modules and shows how the intricate systems of the spacecraft were assembled. The CM capsule was a $33^{\circ}$ half-angle cone with the blunt aft heat shield formed from a segment of a sphere of radius $469.4 \mathrm{~cm}$ (184.8 in). A toroidal section with radius of $19 \mathrm{~cm}$ (7.7 in.) provided the transition between the conical and spherical sections. The maximum capsule diameter of $391 \mathrm{~cm}$ (154 in.) occurred in the toroidal section.

The coordinate system used to describe locations on the Apollo CM is shown in Fig. 2. The figure also presents locations of pressure sensors and calorimeters to quantify the capsule reentry environment during initial orbital test flights. Figure 3 shows a diagram of the hypersonic flowfield surrounding the Apollo spacecraft during reentry including the stagnation region on the aft heat shield as well as the attached (windward) and separated (leeward) flow regions on the conical portion of the capsule. The $90^{\circ}$ angular coordinate location in Fig. 2 corresponds to the windward side of the capsule while the $270^{\circ}$ angular location corresponds to the leeward side.

The Apollo command module was subjected to the most severe reentry environment in the history of manned spaceflight. The command module heat shield was designed based on two entry trajectories, one which maximized the total heat load to the vehicle and the other which maximized the heat flux. The maximum heat load trajectory was a long-range overshoot for which a total peak heat load of $46792 \mathrm{~J} / \mathrm{cm}^{2}\left(41203 \mathrm{Btu} / \mathrm{ft}^{2}\right)$ was predicted for the stagnation region of the aft heat shield ${ }^{4}$ (note that Fig. 4 in Ref. 4 appears to contain a typographical error in the units for heat load). The maximum heat flux trajectory was a short-range undershoot limited to an acceleration of $20 \mathrm{~g}$ based on estimated physiological limits of the human body. ${ }^{5}$ For the maximum heat flux trajectory, a peak heat flux of $793 \mathrm{~W} / \mathrm{cm}^{2}\left(698 \mathrm{Btu} / \mathrm{ft}^{2}\right.$-sec) was predicted near the stagnation region of the aft heat shield. ${ }^{4}$

The unmanned Apollo AS-201 and AS-202 missions were flown to experimentally quantify the reentry environment from LEO by obtaining pressure data for both the aft heat shield and conical heat shield of the capsule as well as heat transfer data for the conical heat shield. The flight pressure data from both missions agreed with wind tunnel tests, and the behavior of the heat transfer measurements agreed with theoretical predictions after considering localized ablative mass injection into the boundary layer. ${ }^{6,7}$ Recent computational fluid dynamic (CFD) analyses of the reentry environment from LEO were performed for the conical portion of the Apollo capsule and demonstrated good agreement with flight data, enhancing confidence in the ability of CFD to predict the reentry environment of the $\mathrm{CEV} .{ }^{8}$ 


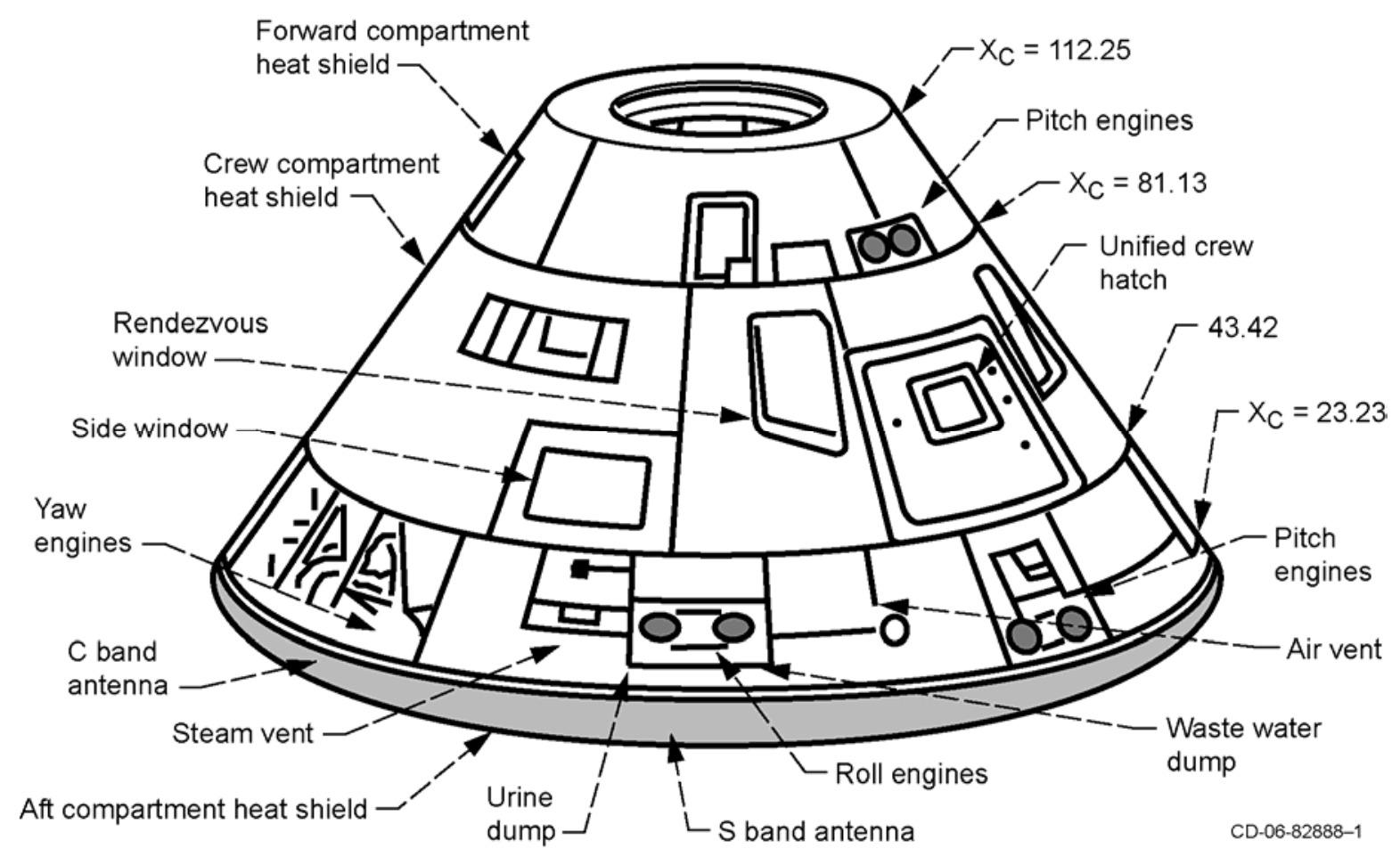

Figure 1. Apollo Block II command module. ${ }^{5}$

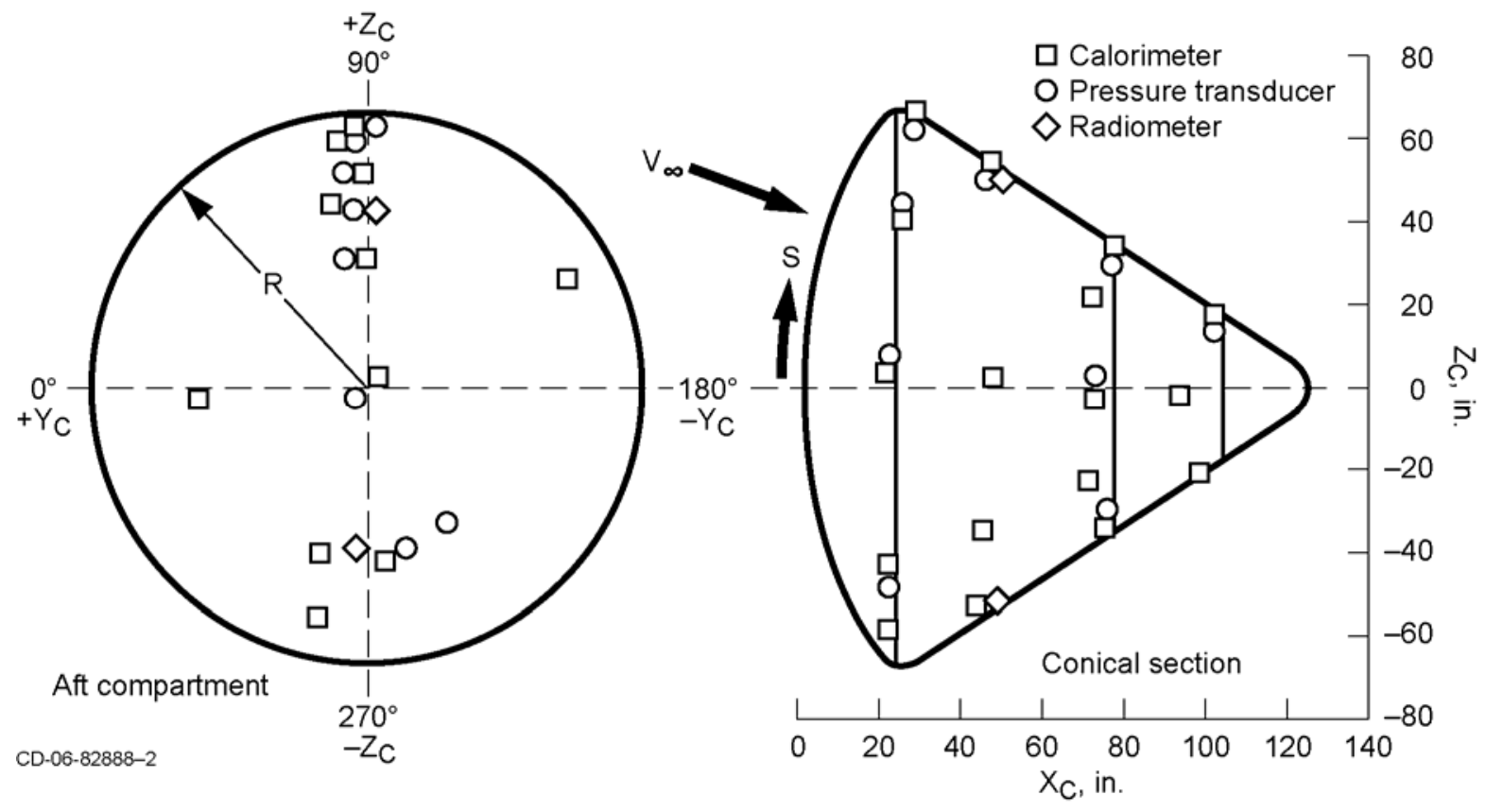

Figure 2. Apollo spacecraft orientation and measurement locations for Apollo 4 and 6. Orbital entry missions AS-201 and AS-202 were configured similarly. ${ }^{4}$ 


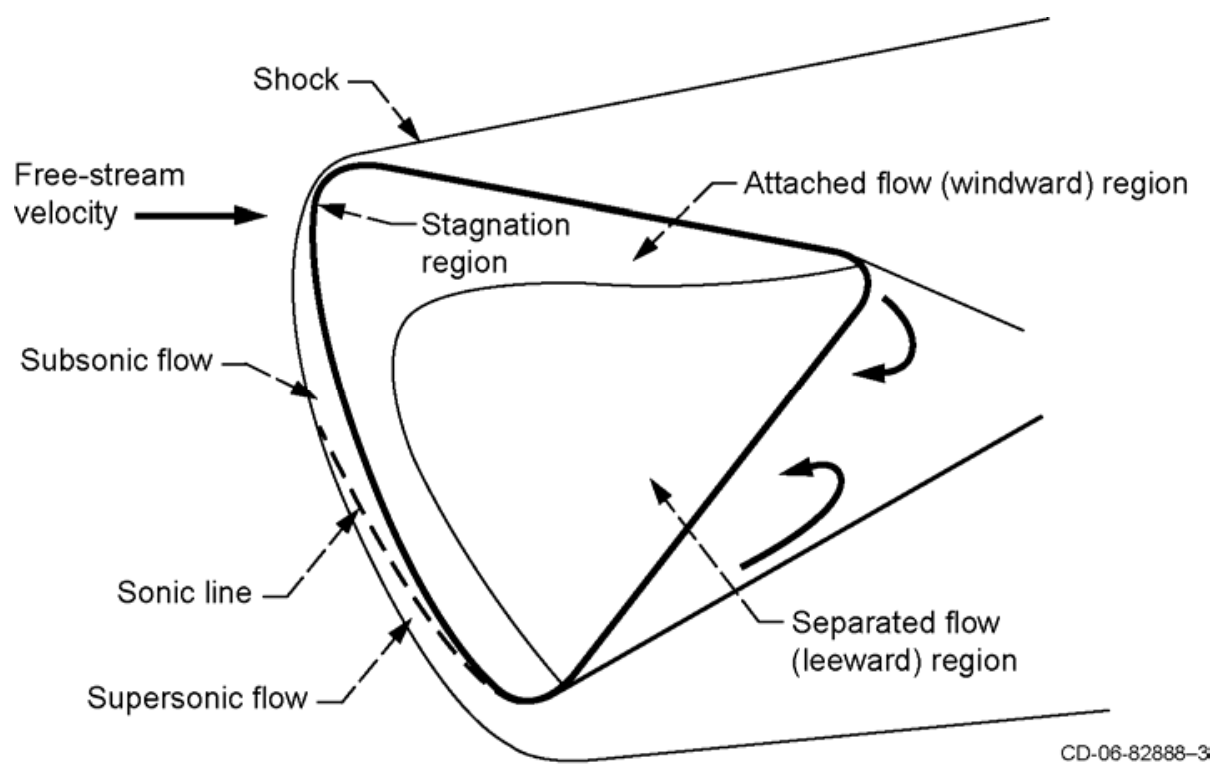

Figure 3. Description of hypersonic flowfield surrounding Apollo command module during reentry.
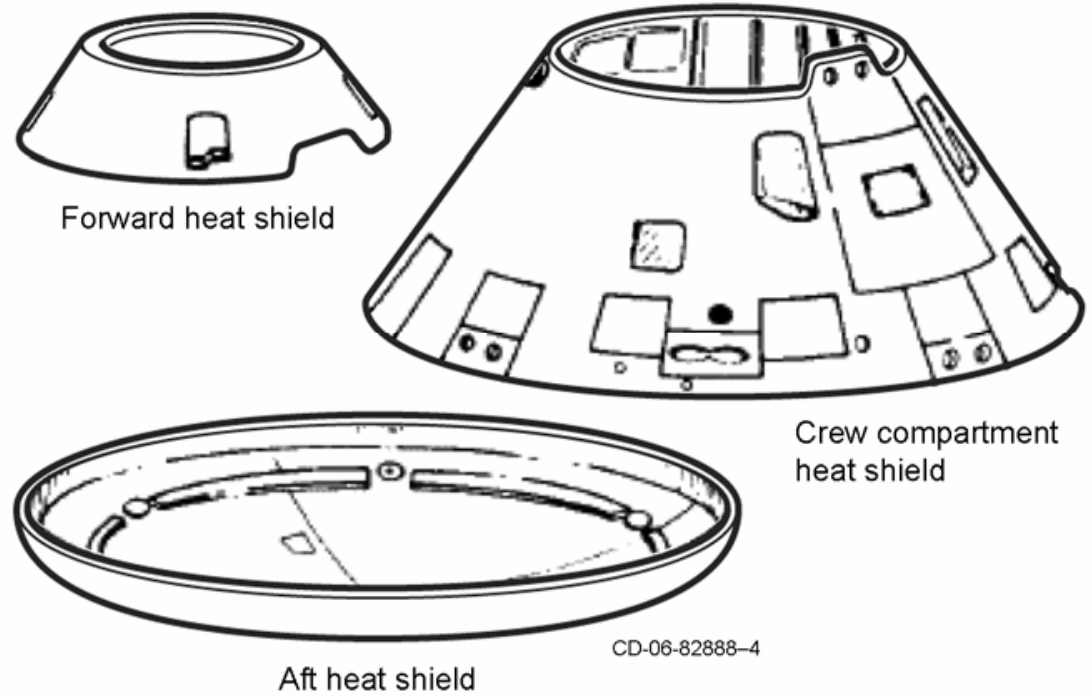

Crew compartment heat shield

Figure 4. Apollo command module heat shield separated into its three components. ${ }^{9}$

Reentry data was also gathered from the unmanned Apollo 4 and 6 superorbital flights which entered the Earth's atmosphere at velocities typical of a direct lunar return. The measured data included pressures, convective heat fluxes, and radiative heat fluxes on both the aft heat shield and the conical heat shields. Flight measurements of heat transfer to the aft heat shield demonstrated good agreement with thermal models both for convective and radiative heating. However, the heat flux and pressure measurements on the conical portion of the command module were lower than predicted, and in fact the heat flux measured on the conical portion of the vehicle was lower for the superorbital reentries than for reentries from LEO. This was attributed to the increased rate of growth of the boundary layer caused by upstream ablative mass injection from the aft heat shield. ${ }^{4,7}$ It should be noted that the 
effects of ablative mass injection for superorbital reentry affected the flight data downstream of the injection region whereas mass injection during reentry from LEO affected only the localized data.

\section{B. Description of the Apollo Command Module Heat Shield}

The all-ablative Apollo TPS heat shield which protected the capsule during reentry was made from a fiberglass honeycomb filled with an epoxy-novalac resin reinforced with quartz fibers and phenolic microballoons. ${ }^{9}$ However, the TPS contained several gaps and penetrations which required additional thermal seals to prevent ingestion of high enthalpy reentry gases. Figure 4 shows the aft heat shield, the crew compartment heat shield, and the forward heat shield which constitute the three command module heat shield subassemblies. As shown in Fig. 5, the aft heat shield was subjected to the highest heating rates and surface temperatures of the three subassemblies and had the greatest thickness of ablator material. The crew compartment heat shield protected the pressure hull and crew cabin from the thermal environment of reentry. The forward heat shield protected the parachutes, floatation balloons, and other equipment located at the top of the vehicle. The forward heat shield was jettisoned at the end of the mission to allow for parachute deployment.

Initially, radiative-cooled metallic shingles were considered for the crew cabin and forward heat shields. However, uncertainties in the heating rate models for the conical section of the command module led to the adoption of the all-ablative TPS design. ${ }^{9}$ Subsequent designs specified that the TPS be composed of multiple pre-formed ablative tiles each approximately $1 \mathrm{ft}^{2}$ in area. Post-mission inspections of Mercury spacecraft heat shields revealed that ablative tile center plugs had failed to completely bond to the substructure. ${ }^{5,9}$ This, when combined with the large uncertainties in the predicted heating rates in gaps between tiles, ${ }^{9}$ resulted in the Apollo command module forgoing the use of pre-formed tiles and instead incorporating a heat shield composed of large sections of fiberglass honeycomb filled with Avcoat 5026-39G ablator. The Gemini spacecraft incorporated a similar filled fiberglass honeycomb heat shield which increased confidence in the design.

The heat shield was manufactured by first bonding the fiberglass honeycomb to a stainless steel honeycomb substructure with HT-424 adhesive tape. ${ }^{9}$ The bond line was inspected to ensure that a good bond had been achieved, and the assembly was then cured. After curing, each of the 370,000 honeycomb cells was manually filled with Avcoat ablator using a device similar to a high pressure caulking gun. ${ }^{10}$ The filled honeycomb was furnacecured, after which it was finish-machined on a numerically controlled lathe. The heat shield was X-ray inspected to find any voids which were subsequently drilled out and refilled with Avcoat ablator material. The completed heat shield and an underlying insulating layer were attached to the command module pressure hull using mechanical fasteners for the aft heat shield and fiberglass slip-stringers for the crew compartment heat shield.

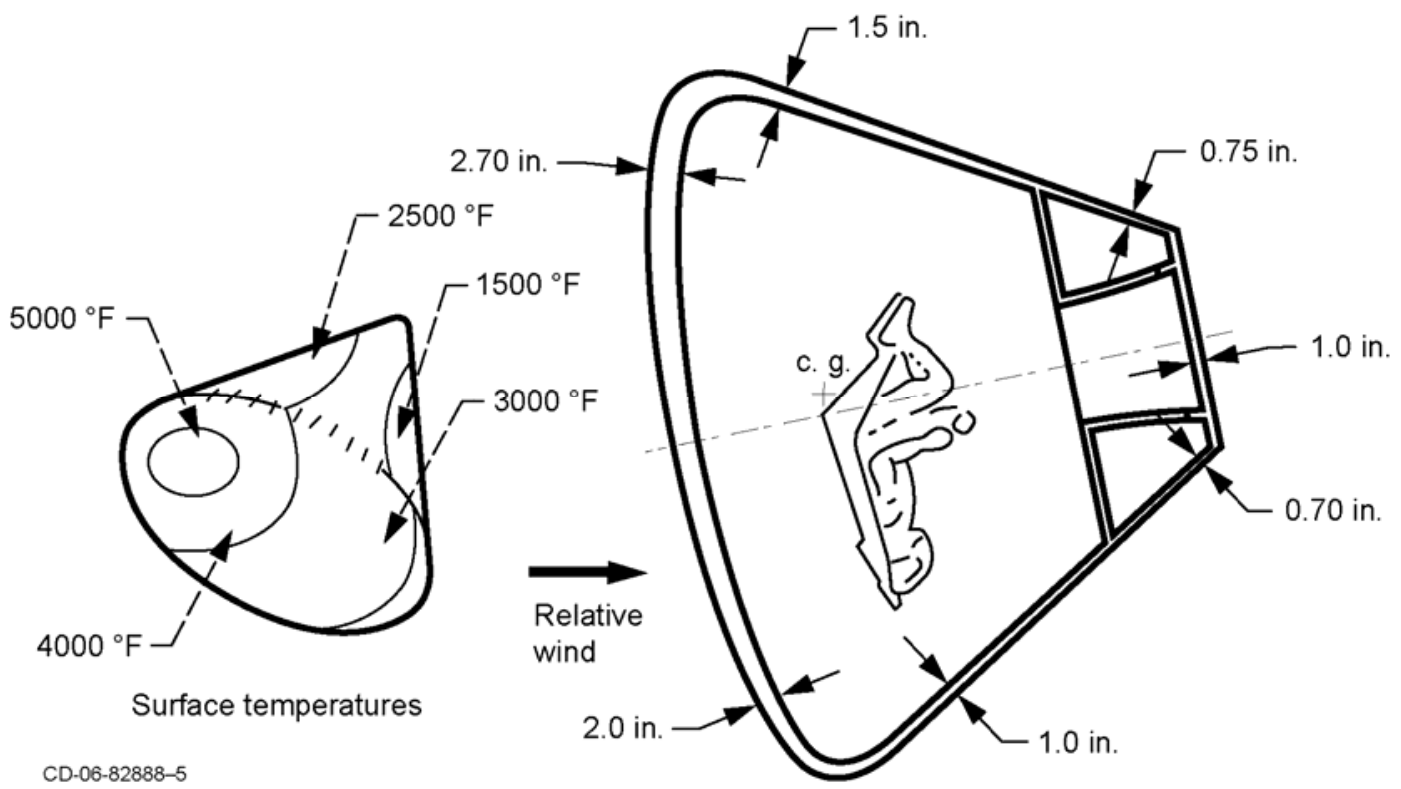

Figure 5. Command Module heat shield temperature distribution and corresponding ablator thickness. ${ }^{9}$ 


\section{Seals for the Thermal Protection System of the Apollo Command Module}

Penetrations through the thermal protection system of the Apollo command module required thermal seals to prevent ingestion of high enthalpy reentry gases. Seals for the thermal protection system were subjected to the high heat fluxes and temperatures of the reentry environment and were therefore constructed from high temperature materials. The following sections review the literature and original Apollo drawings and discuss the designs of various thermal seals for the Apollo command module aft heat shield, crew compartment heat shield, forward heat shield, and the TPS for the Reaction Control System (RCS) motors and access panels.

Most of the thermal seals used on the Apollo command module were composed of high temperature silicones, including room temperature vulcanized (RTV) silicones. High temperature silicones exhibit ablative properties at temperatures exceeding their maximum use temperatures. As described in the following sections, inspections of the seals on the Apollo/Skylab 3 capsule revealed evidence of ablation, particularly for seals in high temperature regions of the aft heat shield and the aft heat shield-to-crew compartment heat shield interface gap.

\section{Aft Heat Shield}

The aft heat shield contained several types of penetrations to allow for attachment of the command module to the service module. Six high-density fiberglass-laminate pads were installed near the outer circumference of the aft heat shield to transfer compressive loads between the service and command modules. Three of the six pads were additionally designed to transfer shear loads and were also accompanied by steel tension tie bolts which passed through the ablative heat shield and were fastened to the command module's aluminum substructure. A section view of a compression pad with an accompanying tension tie bolt is shown in Fig. 6. The outer circumference of a tension tie bolt was sealed with RTV to prevent ingestion of high enthalpy reentry gases, and a layer of Marionite insulation prevented excessive thermal conduction from the tension tie bolt to the surrounding stainless steel substructure. Prior to reentry, explosive charges were used to break the tension tie bolts and separate the service module from the command module. ${ }^{11}$ During reentry, the exposed tips of the tension tie bolts melted flush with the surrounding fiberglass pads while the temperature measurements at the bases of the bolts showed no significant responses. ${ }^{5}$ One of the compression pads can be seen on the Apollo 11 command module shown in Fig. 7 , although it appears that the molten tension tie bolt was removed after recovery of the vehicle as part of the post-mission inspection of the heat shield.

In addition to the fiberglass compression pad and the tension tie bolt location, Fig. 7 also shows the locations of two ablator plugs used to protect the mechanical fasteners attaching the aft heat shield to the command module structure. A section view of the ablator plug and mechanical fastener is shown in Fig. 8. The outer circumference of the ablator plug does not appear to have been sealed because of the close tolerance between the access hole and the ablator plug as well as the minimal flow rate through the circumferential gap due to flow stagnation at the base of the hole. Figure 9, a photograph of an ablator plug location on the Apollo/Skylab 3 command module, shows no evidence of a seal or seal material around the circumference of the hole. The location in the photograph appears to be oversized from the drawing and may represent post-mission destructive removal of the ablator plug.

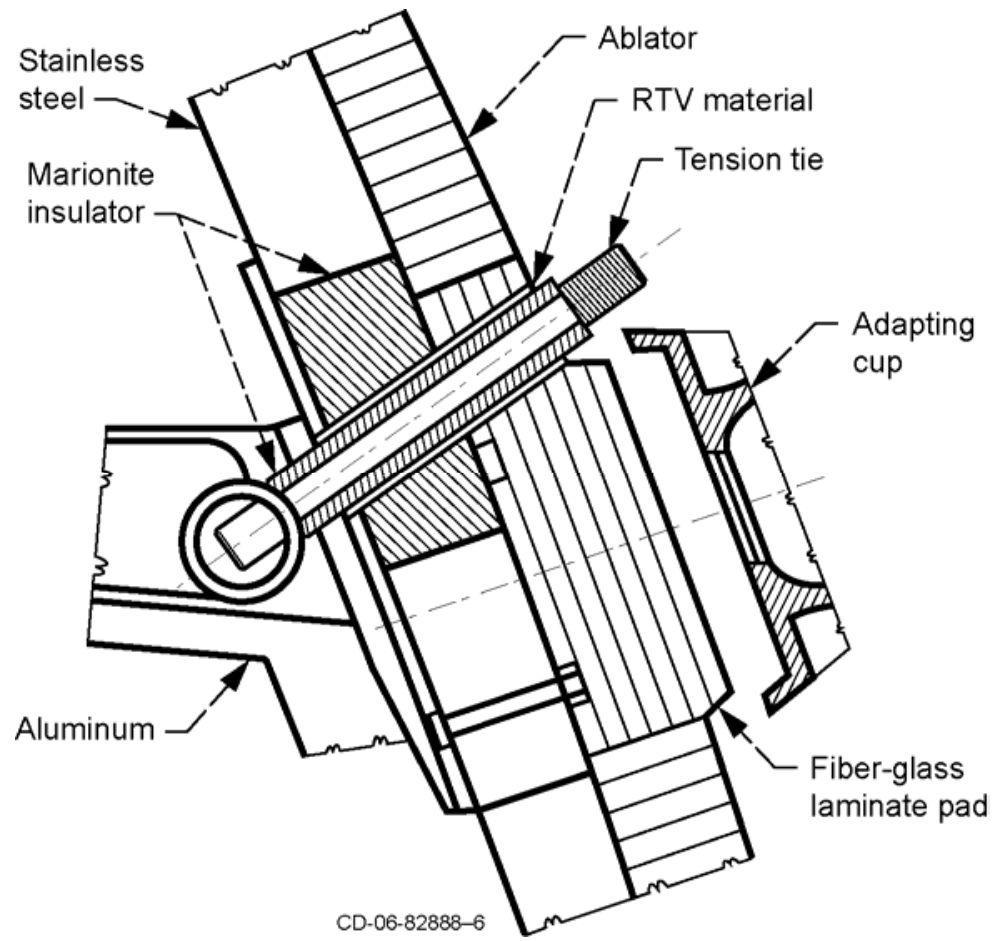

Figure 6. Sectional view of shear pad and tension tie bolt used to transfer loads from Service Module to Command Module. ${ }^{5}$ 


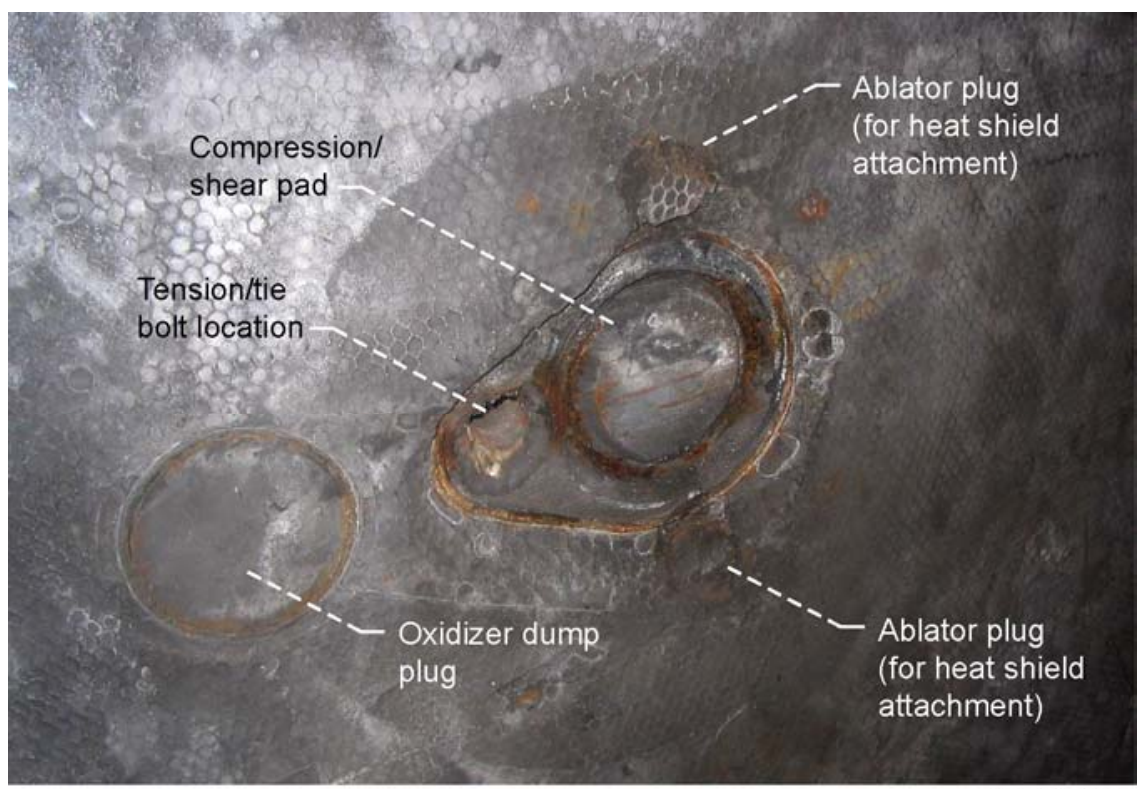

CD-06-82888-7

Figure 7. Photograph of Apollo 11 heat shield penetrations for attachment of command module to service module.

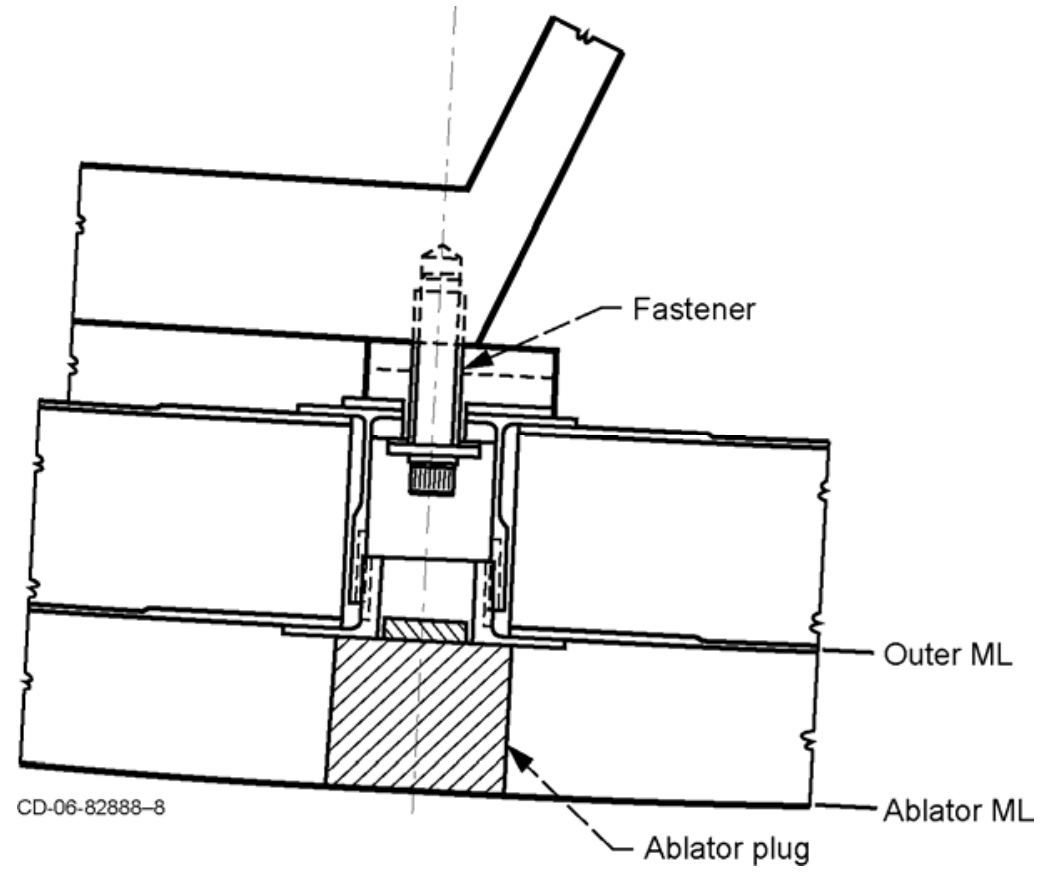

Figure 8. Mechanical attachment of heat shield to substructure with protective ablator plug (from Apollo drawing V36-320000).

Figure 7 shows the plug covering the oxidizer dump port on the Apollo 11 command module, and Fig. 10 shows the plug covering the fuel dump port on the Apollo/Skylab 3 command module. The gaps introduced into the aft heat shield by these plugs were sealed with high temperature GE RTV $560^{12}$. During an abort within the first 42 seconds after liftoff, the oxidizer and fuel dump plugs would be jettisoned using small pyrotechnic charges. ${ }^{11}$ The RCS monomethylhydrazine fuel and nitrogen tetroxide oxidizer would then be dumped through the ports to ensure that they would not pose a fire or chemical hazard to the astronauts and recovery crews. ${ }^{13,14}$ Note that the seals shown in the two figures show strong evidence of ablative mass loss at their outer surfaces. 


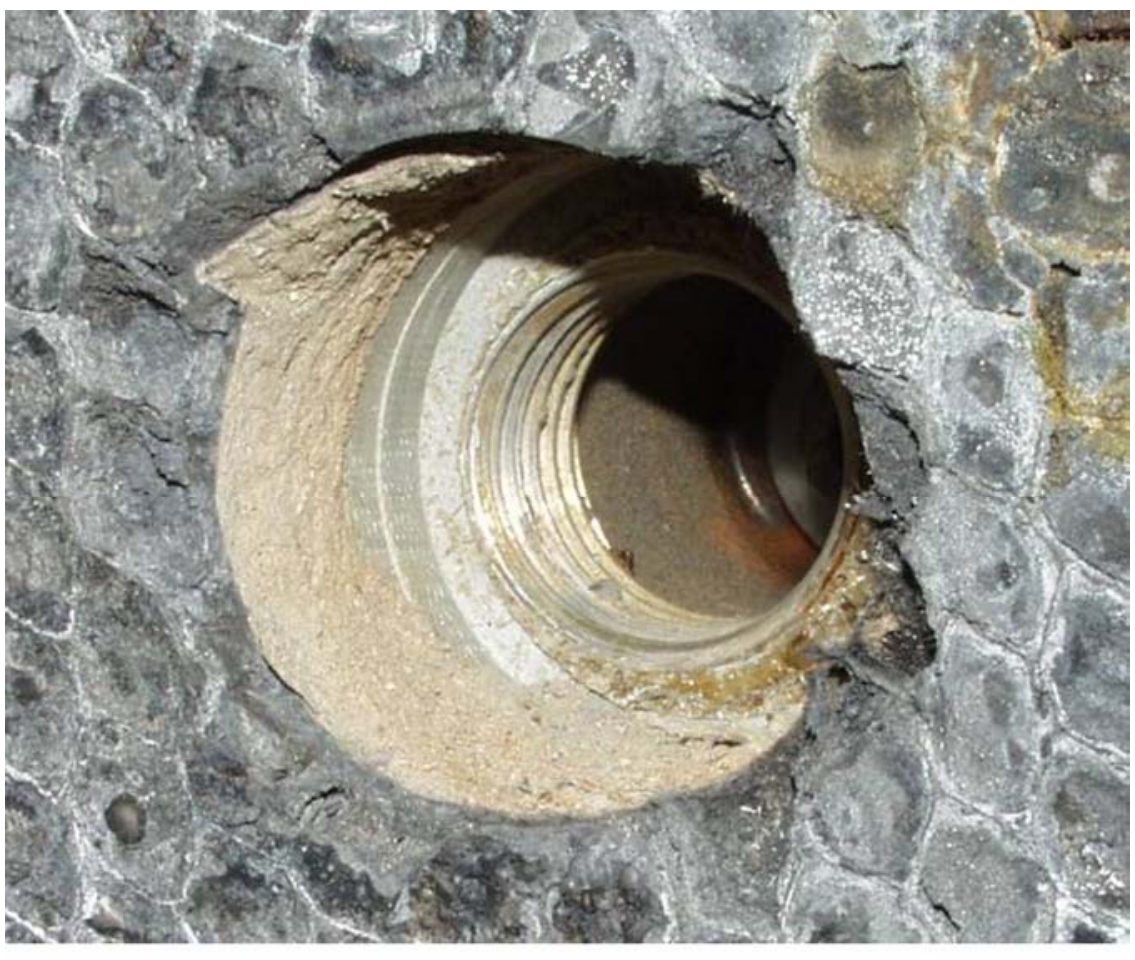

CD-06-82888-9

Figure 9. Photograph of ablator plug hole on Apollo/Skylab 3 aft heat shield.

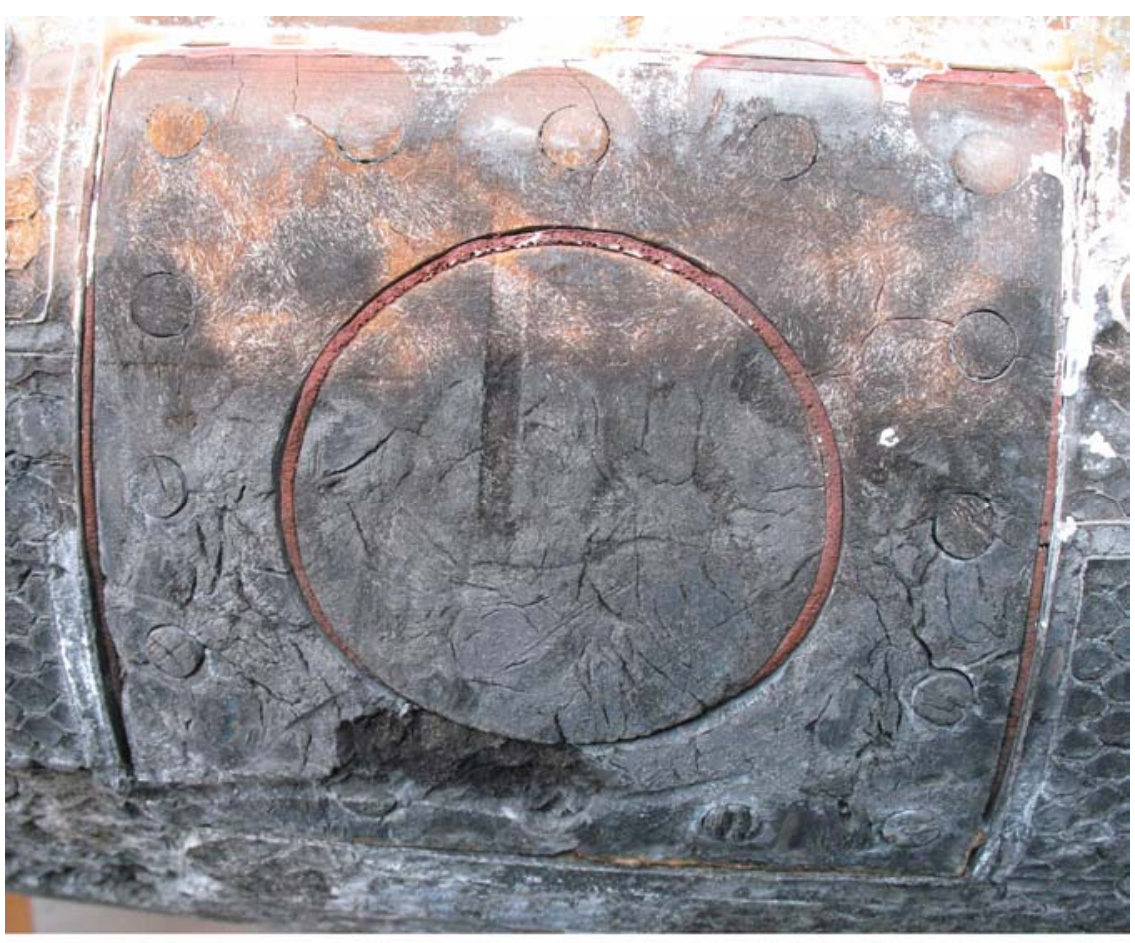

CD-06-82888-10

Figure 10. Photograph of RCS fuel dump plug on Apollo/Skylab 3 command module. 


\section{Aft Heat Shield-to-Crew Compartment Heat Shield Interface Gap}

The aft heat shield-to-crew compartment heat shield interface gap was located in a region of high heat flux gradient both in the axial direction and around the circumference of the capsule. Figure 11 shows two schematic diagrams of the Apollo capsules with heat flux measurements shown near the aft heat shield-to-crew compartment heat shield interface gap. Heat flux data from the unmanned orbital test flight AS-201 are shown in Fig. 11(a), and heat flux data from the unmanned superorbital test flight Apollo 4 are shown in Fig. 11(b). Heat flux measurements upstream of the interface gap (i.e., on the aft heat shield) were much higher than those downstream of the gap. This demonstrates the high gradient in the axial direction. In addition, the heat fluxes were larger on the windward side of the vehicle (i.e., $\left.90^{\circ}\right)$ than the leeward side of the vehicle $\left(270^{\circ}\right)$ for the same axial locations. While this is only partially clear from the selected heat flux measurements shown in this paper, the broad range of heat flux data presented in Refs. 4 and 6 fully demonstrate the dependence of the heat flux on the angular position. Another interesting fact is that the heat flux at the $138^{\circ}$ location on the AS-201 vehicle $\left(11 \mathrm{~W} / \mathrm{cm}^{2}\right)$ was higher than the heat flux at the identical location on Apollo $4\left(9 \mathrm{~W} / \mathrm{cm}^{2}\right)$. This illustrates the general trend observed during the Apollo test flights ${ }^{4,6,7}$ whereby the heat flux to the conical section of the Apollo 4 capsule was lower than that of the orbital test flights. This was attributed to the increased rate of growth of the capsule boundary layer caused by increased ablative mass injection rate from the aft heat shield during superorbital reentry. ${ }^{4,7}$

The interface gap between the aft heat shield and crew compartment heat shield was sealed with two elastomer gaskets as shown in Fig. 12. The inner gasket (Fig. 12a) was formed first and sealed the gap between the upper stainless steel honeycomb structure and the adjoining lower connection ring. Versilube G-300 (a release agent) was first applied to the crew compartment stainless steel honeycomb surface. The aft heat shield and crew compartment heat shield were attached to the command module using mechanical fasteners and fiberglass slip-stringers, respectively. Then, a silicone material was applied to the connection ring surface and was allowed to cure in place. Engineers working on this project at the time recall the silicone material to be GE RTV 560. ${ }^{12}$ After the silicone had cured, the aft heat shield was detached from the command module which pulled the elastomer gasket away from the crew compartment heat shield sealing surface. An identical process was used to form the outer gasket (Fig. 12b) in the gap between the ablator sections of the two heat shields. A photograph of the outside of the aft heat shield-tocrew compartment heat shield interface region including the elastomer gasket is shown in Fig. 13. Of particular note is the rough appearance of the gasket outer surface caused by ablation at high temperatures.

The primary difference in shape between the inner and outer gaskets was that the inner gasket sealed around a "V"-shaped tooth which was machined into the crew compartment heat shield stainless steel honeycomb. This tooth served two functions. First, it provided a means of aligning the aft heat shield to the rest of the vehicle prior to attaching the heat shield with mechanical fasteners. The tooth ensured that the outer surface of the interface gap would not have any forward or rearward facing steps which would increase localized heating. Second, the tooth would function as a labyrinth seal tooth and form a tortuous flow path in the event of a gasket breech.

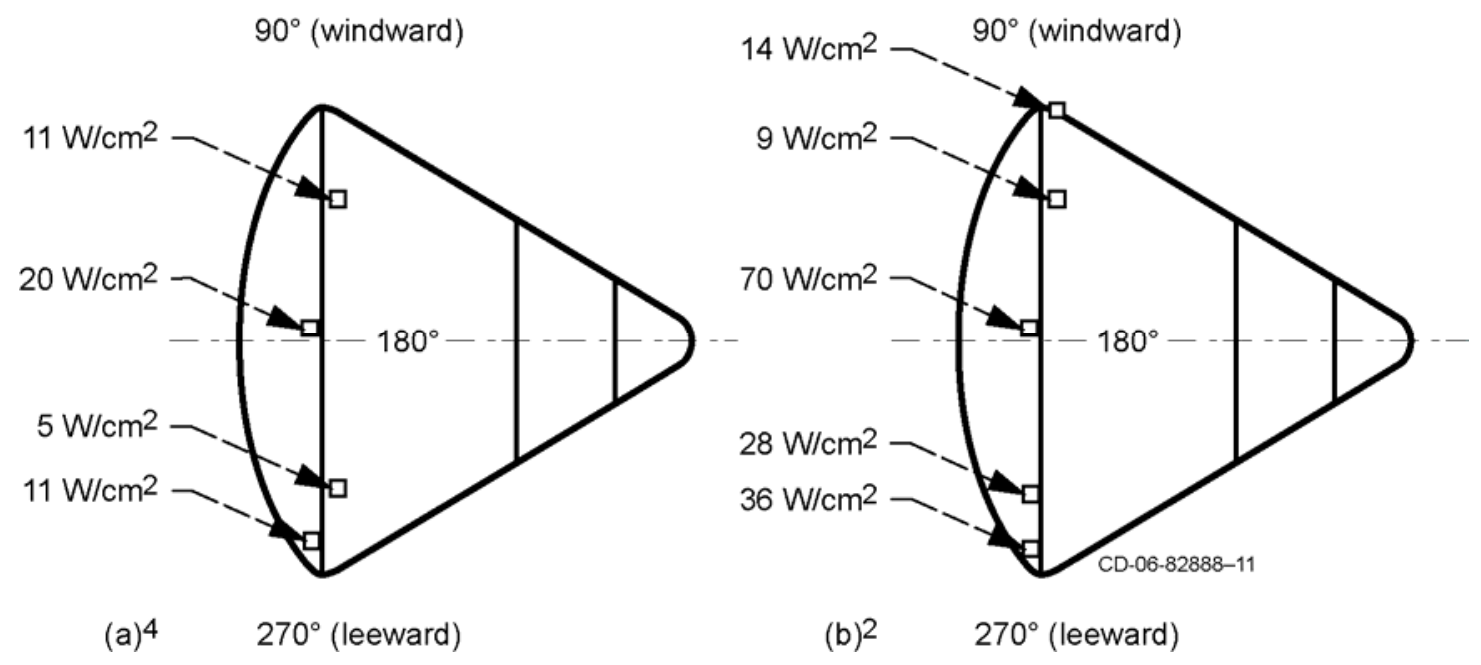

Figure 11. Heat flux measurements near the aft heat shield-to-crew compartment heat shield interface gap from the (a) AS-201 orbital mission, and (b) Apollo 4 superorbital mission. 


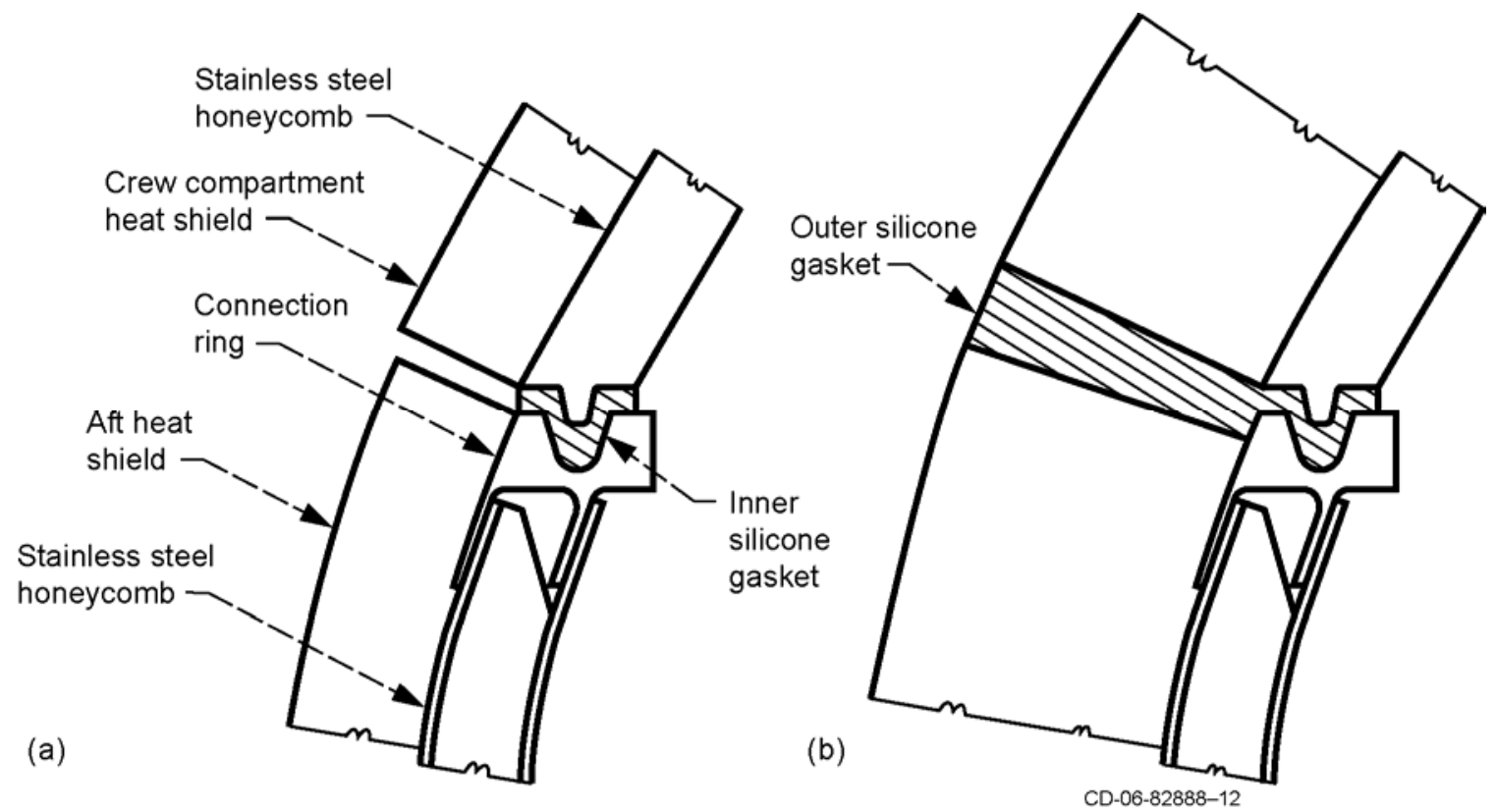

Figure 12. Section drawings of silicone gasket used in Apollo heat shield-to-crew compartment heat shield interface gap (from Apollo drawings V16-320000 and V36-320000).

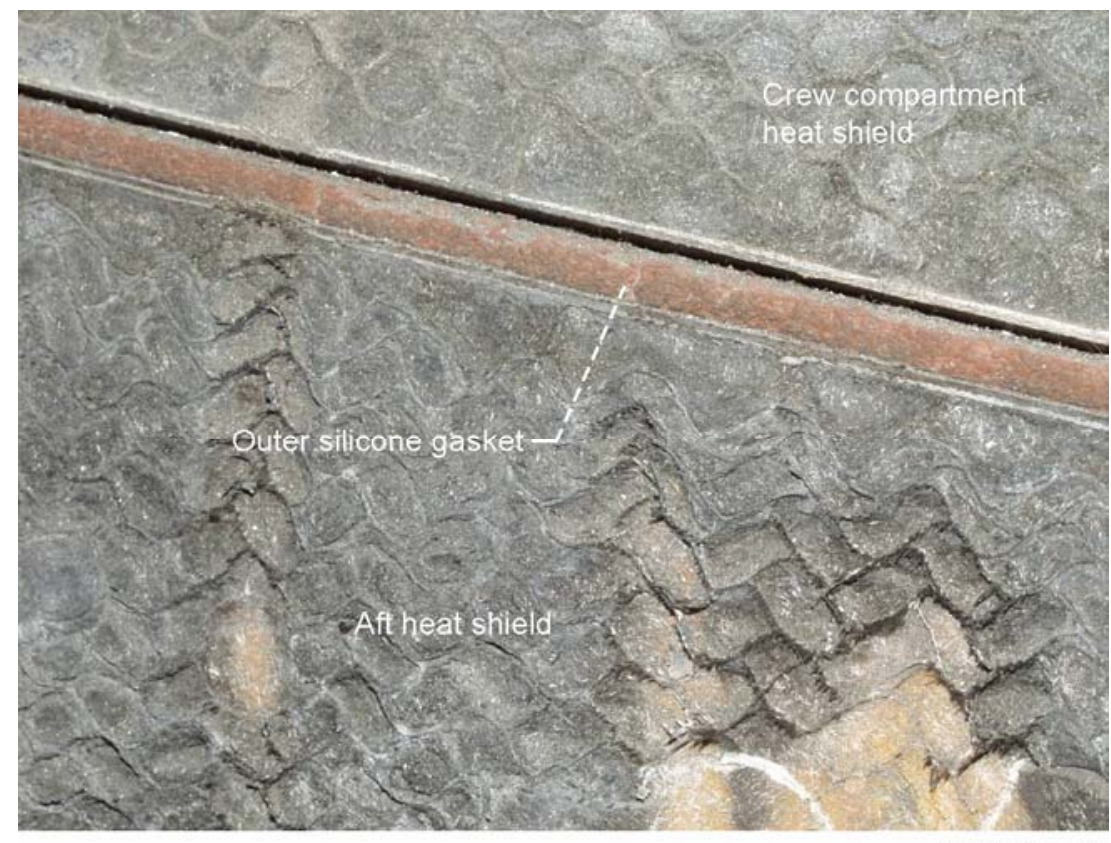

CD-06-82888-13

Figure 13. Photograph of Apollo/Skylab 3 aft heat shield-to-crew compartment heat shield interface region including the outer silicone gasket seal.

\section{Crew Compartment Heat Shield}

The crew compartment heat shield contained several penetrations both for access to the interior of the vehicle and for the RCS motors. After the crew compartment heat shield was attached to the command module, RTV $560^{12}$ was poured into the gaps around the access panels and the RCS nozzles where it was allowed to cure in place. ${ }^{5} \mathrm{~A}$ photograph of one of the Apollo/Skylab 3 RCS roll motors and its associated RTV seals is shown in Fig. 14. The RCS motor was mounted into an access panel which also included RTV seals around its perimeter. Figure 15 shows 
a close-up view of the corner of a similar access panel. The outer perimeter seal appears to have been cut with a razor along its inner perimeter presumably for post-flight servicing and inspection of the internal components. Of particular note is that unlike the silicone-based thermal seals located on the aft heat shield and the aft heat shield-tocrew compartment heat shield interface gap, the silicone seals on the crew compartment heat shield exhibit little evidence of ablation and qualitatively demonstrate the relatively benign thermal environment imposed upon the crew compartment heat shield.

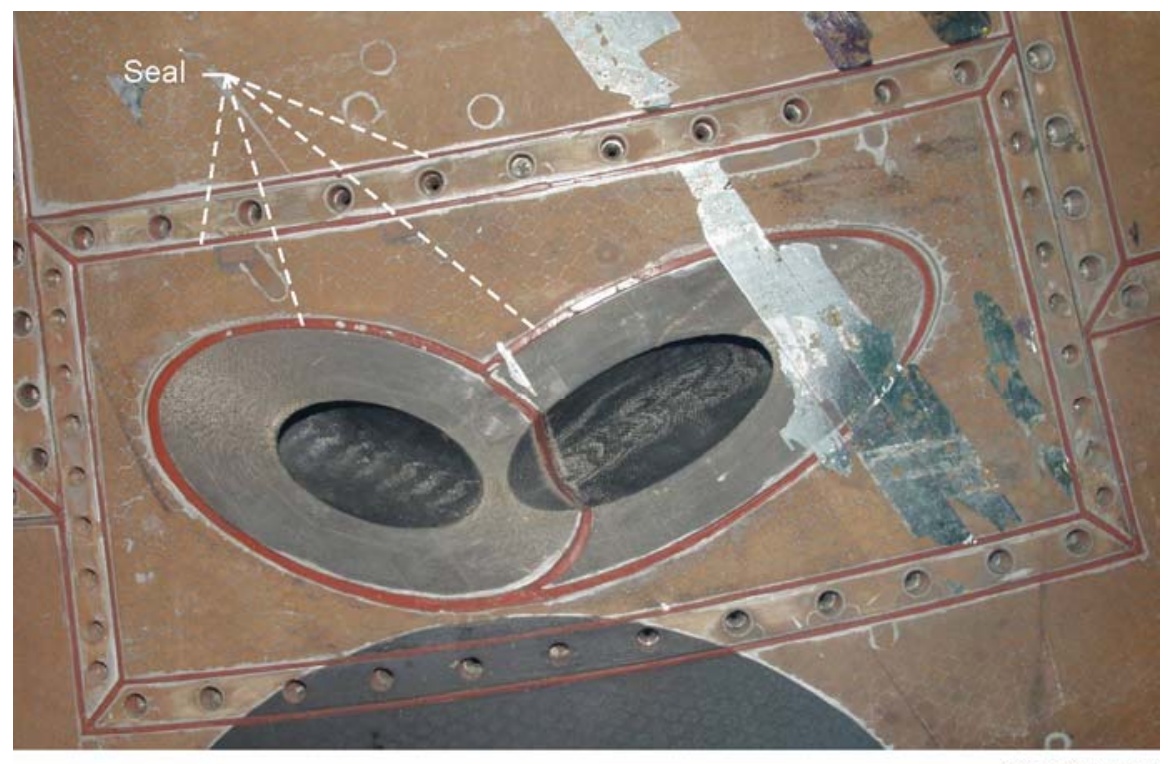

Figure 14. Photograph of Apollo/Skylab 3 RCS roll motors showing silicone thermal seals.

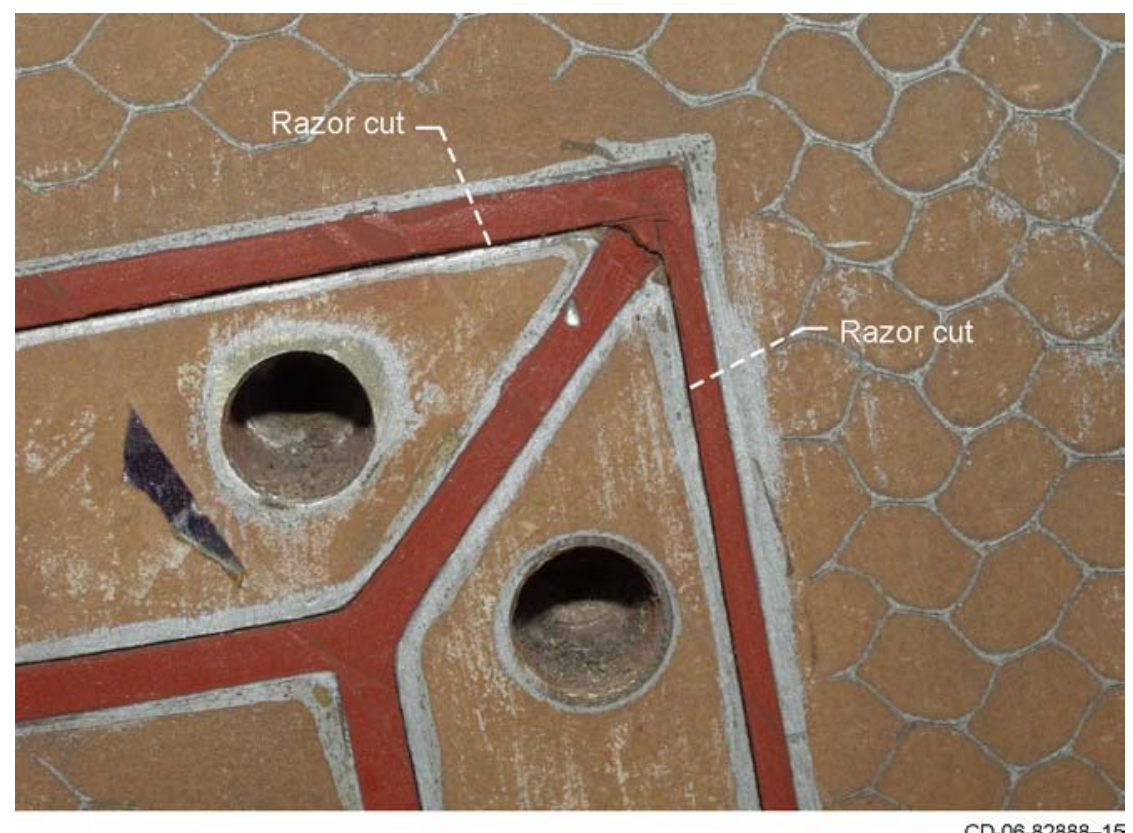

Figure 15. Photograph of Apollo/Skylab 3 access panel corner emphasizing silicone thermal seal. The seal contains razor cuts presumably to allow panel removal. 


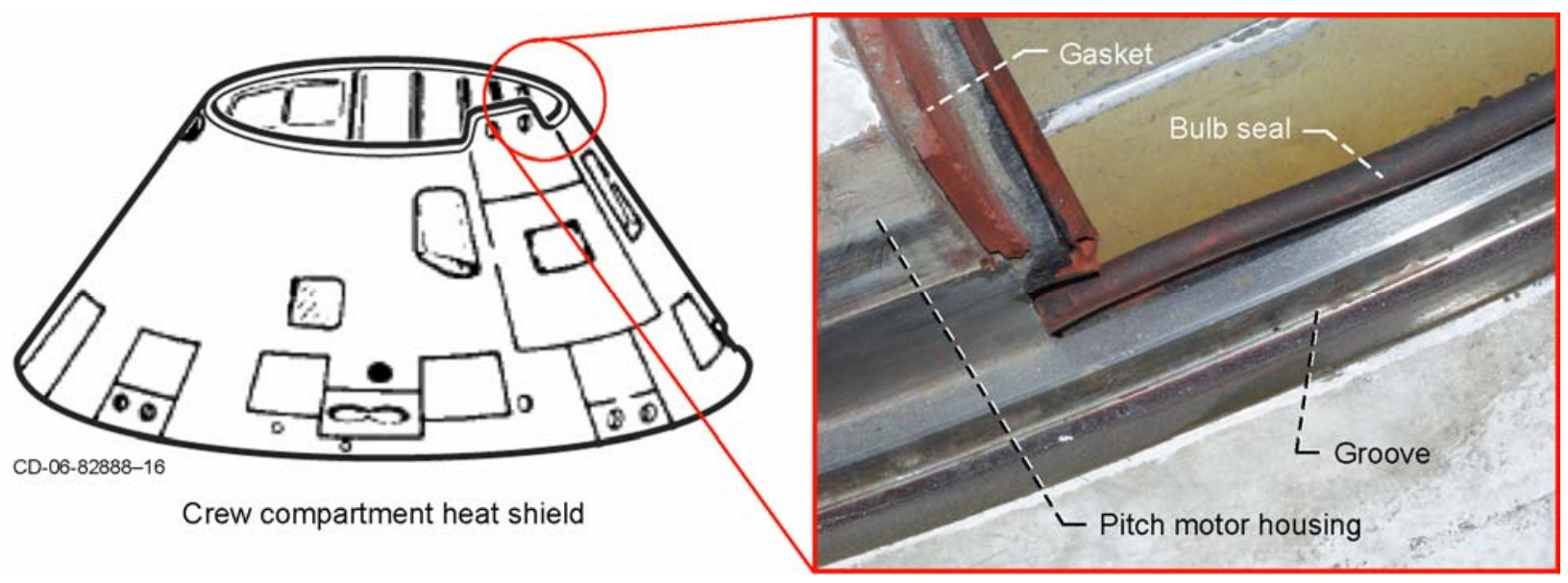

Figure 16. Downward-looking photograph of top of Apollo/Skylab 3 vehicle showing forward heat shield mounting location and seals.

\section{Forward Heat Shield}

The forward heat shield was separated from the crew compartment heat shield by a small gap which required seals to prevent ingestion of reentry gases. Since the forward heat shield was jettisoned prior to parachute deployment, it could not adhere to the crew compartment heat shield. However, the low heat transfer rates measured on the forward heat shield mitigated the adhesion concerns. Most of the gap circumference between the two heat shields was sealed with an elastomer bulb seal (engineers working on the project at the time recall this to be heat vulcanized elastomer gum stock per ZZ-R- $765^{12}$ ) which is shown on the right side of Fig. 16, a downward-looking photograph of a portion of the forward compartment of the Apollo/Skylab 3 capsule. The groove outboard of the seal appears to have served as a seating location for the forward heat shield.

Figure 16 also shows the side of the upper RCS pitch motor which was housed in the forward compartment of the command module. The forward heat shield included a conformal notch which fit around the perimeter of the upper RCS pitch motor as shown in Fig. 4. Both sides of the RCS motor were sealed with silicone gaskets, and the lower corner of the motor appears to have been sealed with molded silicone.

Finally, it should be noted that the seals in Fig. 16 appear to have been exposed to low heat loads evidenced by the apparent lack of thermal damage on their outer surfaces. This is expected in light of the low heating rate measurements on the forward heat shield during the unmanned test flights of the command module., ${ }^{4,6}$

\section{Seals for Penetrations of the Apollo Command Module Crew Cabin}

The Apollo command module pressure hull contained several penetrations which required seals to prevent the loss of habitable cabin atmosphere. The leakage rate of each command module was carefully measured before its mission and enough spare oxygen was carried in the service module to account for any losses. All of the Apollo command modules and lunar modules were leak-tested on the ground to confirm a specified maximum allowable leakage of $4.8 \mathrm{lb} /$ day of air. ${ }^{15}$

The following section first discusses the atmosphere in the crew cabin pressure hull to describe the environment against which the seals had to function. Descriptions of the seals used to contain the pressure in the Apollo crew cabin are presented next, including the RTV seals used along riveted and bolted joints, seals for the two hatches, and seals for the telescope and sextant assembly.

\section{Description of the Apollo Command Module Crew Cabin Atmosphere}

For lunar missions, the cabin atmosphere of the Apollo command module was composed of $100 \% \mathrm{O}_{2}$ at a pressure of 5 psi, slightly higher than the partial pressure of oxygen at standard temperature and pressure (STP) of roughly 3.4 psi but below the pressure at which oxygen toxicity becomes a concern (note that Skylab missions used a 5-psi atmosphere composed of $30 \% \mathrm{~N}_{2}$ to reduce the risk of fire). The low cabin pressure provided several benefits to the Apollo capsules. First, the additional weight of inert gases (e.g., nitrogen) did not have to be carried into orbit thus reducing the overall vehicle launch weight. Also, the walls of the Apollo command module and lunar module 
could be made lighter than designs for a cabin pressure of 14.7 psi. Finally, the $100 \%$ oxygen environment had precedent in that it had been successfully flown on the Mercury and Gemini missions.

The fire on Apollo 1 demonstrated the dangers of a 100\% oxygen atmosphere. In atmospheric air, nitrogen gas slows the rate of fire propagation by absorbing some of the heat which would otherwise be transferred to oxygen. It also slows the rate of combustion by reducing the mean free path of the oxygen molecules and slowing the rate at which they reach the combustion surface. ${ }^{16}$ To slow the spread of possible cabin fires while on the launch pad, all manned Apollo missions after Apollo 1 were launched with a cabin atmosphere of 15 psi composed of $40 \% \mathrm{~N}_{2}$ and $60 \% \mathrm{O}_{2}$. Once the capsule reached orbit where the risk of fire was reduced, the cabin pressure was allowed to slowly leak down to the nominal atmosphere of $100 \% \mathrm{O}_{2}$ at 5 psi.

As mentioned above, the leakage out of the Apollo capsules was measured on the ground before flight. The capsules were pressurized to $5.1 \mathrm{psig}$ with air, and the subsequent pressure decay was recorded over a period of time. It was determined that leakage measurements from ground tests were lower than leakage measurements while in orbit; this was due to the increased cabin atmospheric density in ground tests due to the higher absolute pressure ( $\sim 20$ psia for ground tests vs. 5 psia in space), and that the critical pressure ratio across the leakage paths was exceeded while the capsule was in space. ${ }^{15}$

\section{Riveted and Bolted Joints}

Aluminum panels in the Apollo command module were riveted or bolted together to form portions of the pressure hull and were sealed with RTV. A typical RTV-sealed joint between two aluminum panels can be seen in the photograph of the inside of the Apollo/Skylab 3 forward tunnel in Fig. 17. In this case, white RTV was used to seal the joint between multiple panels. It is thought that RTV-sealed joints such as the one shown in the figure accounted for the majority of unplanned atmospheric losses from the Apollo command module. ${ }^{15}$

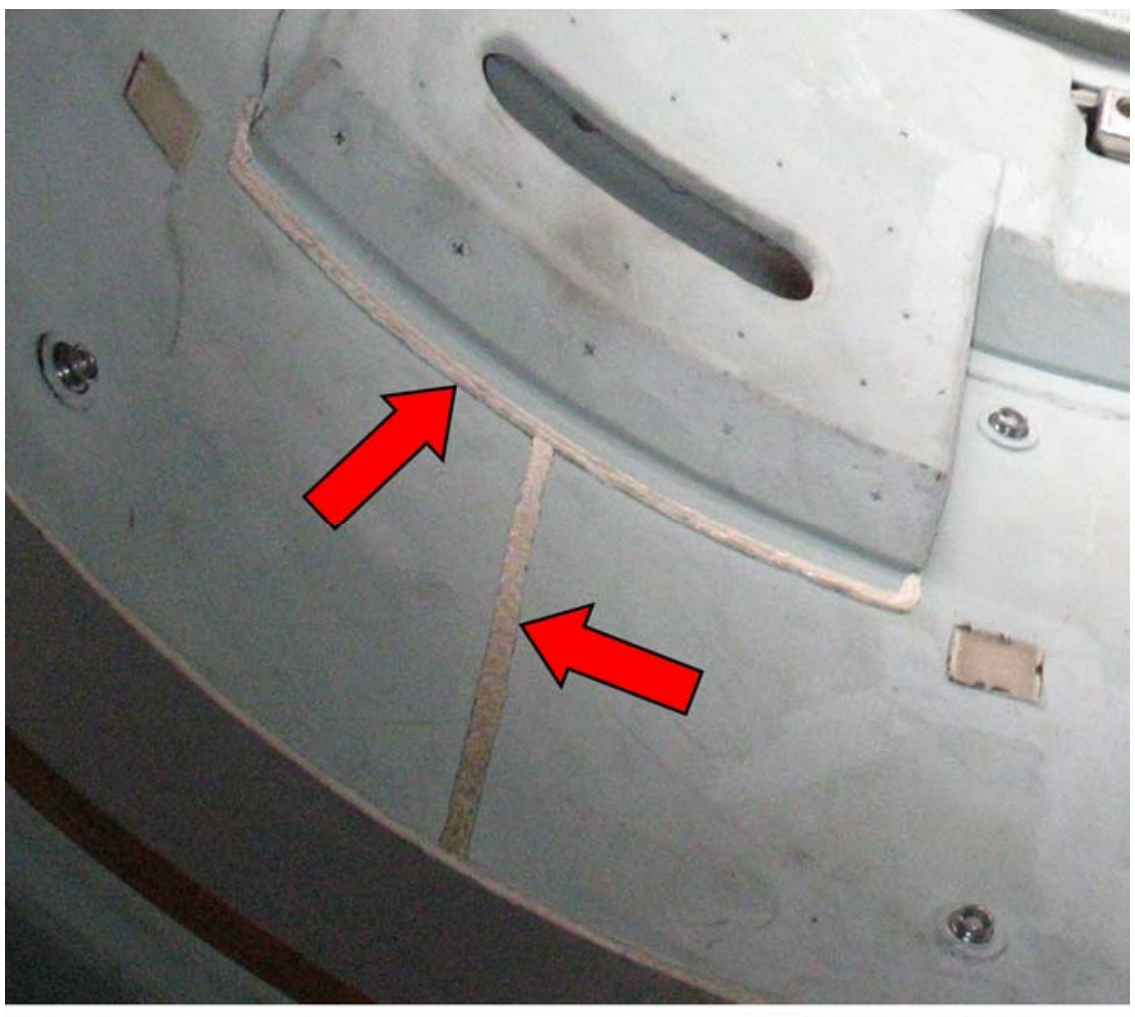

CD-06-82888-17

Figure 17. RTV-sealed aluminum joint inside the Apollo/Skylab 3 forward tunnel. 


\section{Unified Crew Hatch}

The Apollo Unified Crew Hatch (UCH) was designed and implemented in response to the inability of astronauts Grissom, White, and Chaffee to quickly egress from the Apollo 1 fire. The newly designed hatch combined the previously-separated pressure hatch and heat shield hatch into a single, outward-opening hatch. The new hatch could be opened in 3 seconds and all three astronauts could egress in under 30 seconds. ${ }^{17,18}$ A photograph of the UCH from Apollo 11 is shown in Fig. 18. A schematic drawing showing the overhead view of a partially-open UCH is shown in Fig. 19 and illustrates both the pressure seal and the thermal seal used on the hatch.

Although the UCH was located on the leeward side of the capsule during reentry and was therefore subject to low thermal loads, a thermal lip seal was included to prevent ingestion of reentry gases into the gap around the hatch perimeter. A photograph of the Apollo/Skylab 3 mission command module UCH and its high-temperature silicone thermal seal is shown in Fig. 20. Figure 19 shows that the thermal seal was in contact with the hatch frame at a contact angle such that it was angled toward the outboard side of the capsule. During ascent, air in the cavity between the pressure seal and the thermal seal could escape across the thermal seal because the differential pressure would reduce the contact pressure of the thermal seal. This cavity was therefore maintained at near-vacuum conditions during a mission. During reentry, the external pressure on the seal would increase and thereby increase the contact pressure of the seal against the hatch frame. This enhanced the effectiveness of the thermal seal.

The pressure seal on the Apollo UCH was composed of an elastomer gasket attached to the command module hatch frame and an adjoining knife edge formed into the $\mathrm{UCH}$ perimeter. The knife edge can be seen on the outer perimeter of the hatch door in Fig. 18 immediately outboard of the latches and linkage mechanism. The knife edge embedded into the elastomer gasket when the door was fully closed, forming an effective pressure seal. Figure 21 shows a photograph of the Apollo/Skylab 3 hatch frame with the elastomer gasket highlighted. A line of discoloration can be seen on the gasket where the hatch knife edge came into contact with the elastomer surface.

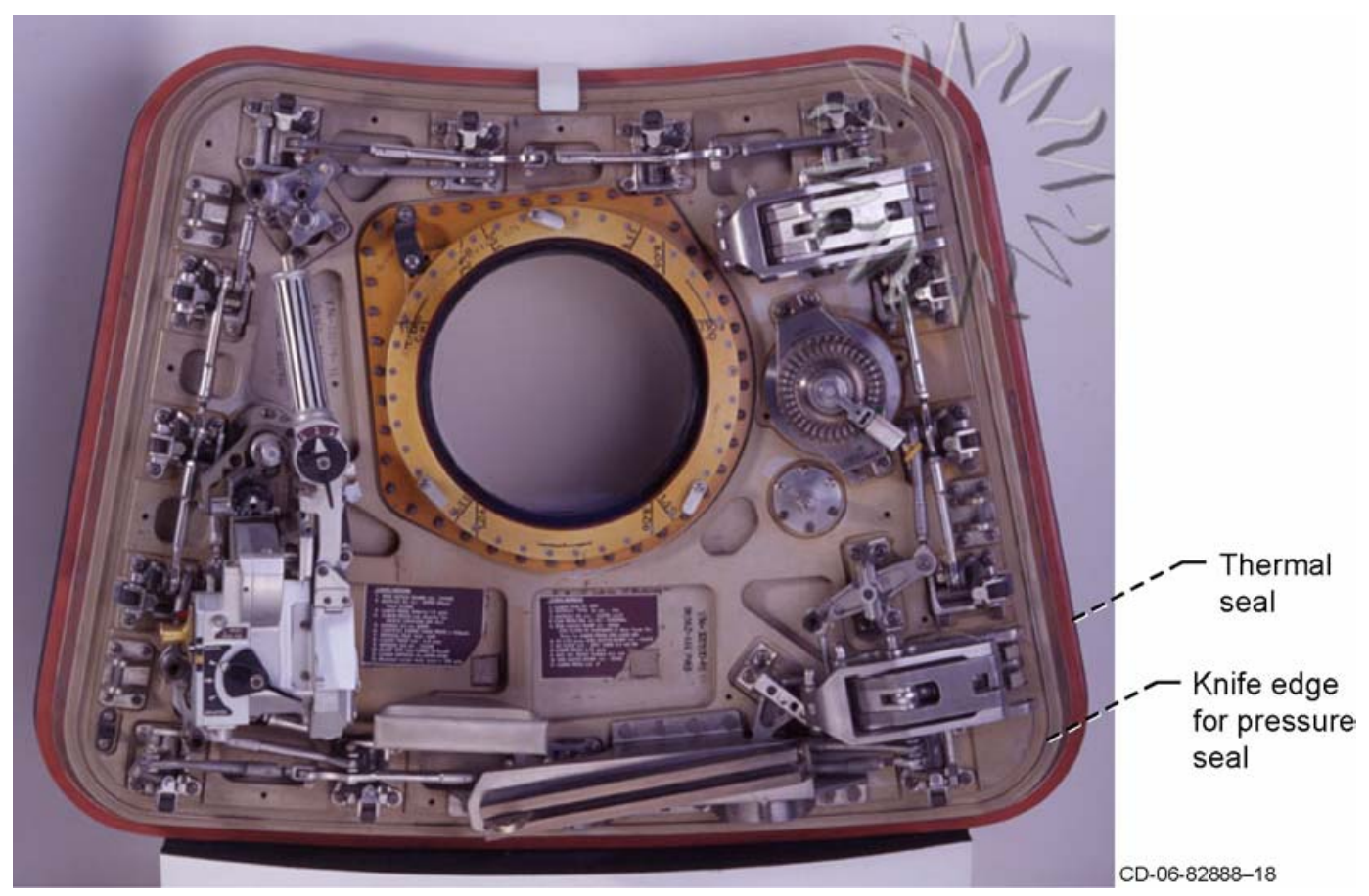

Figure 18. Photograph of Apollo 11 Unified Crew Hatch (National Air and Space Museum photograph 99-15152-6). 


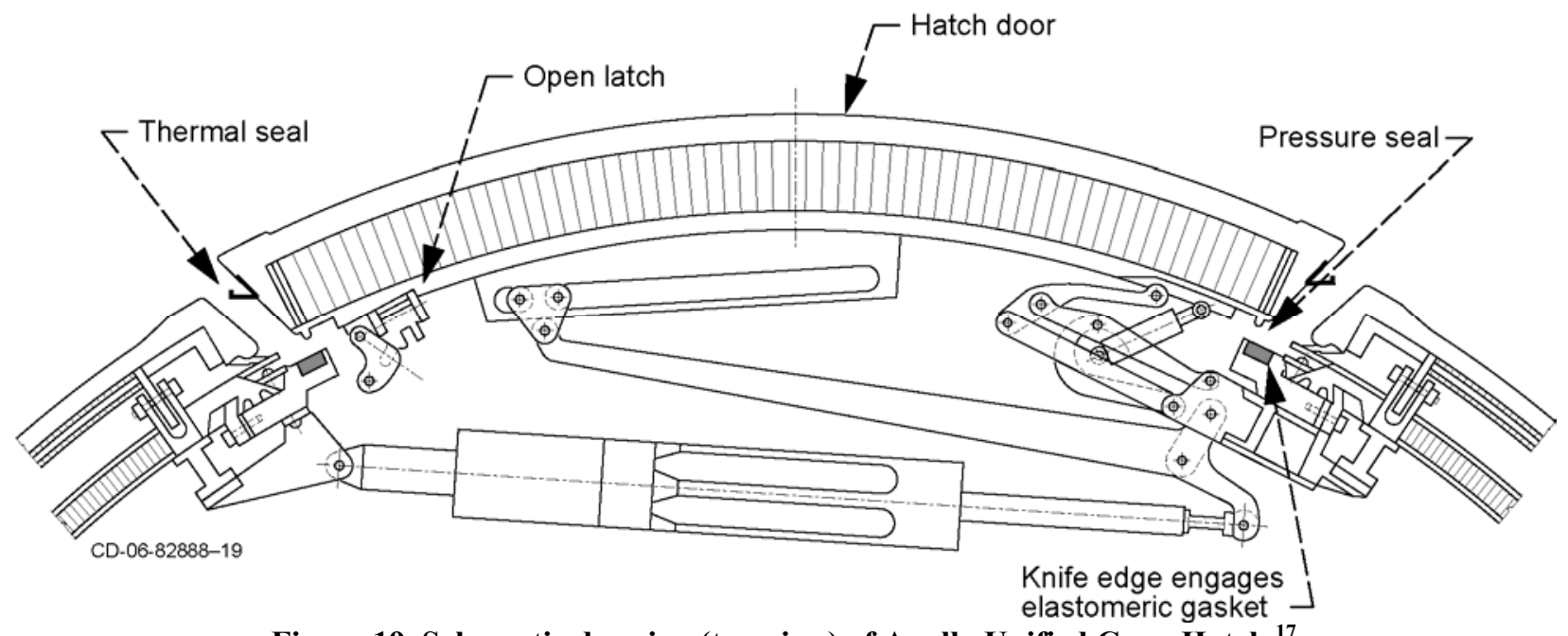

Figure 19. Schematic drawing (top view) of Apollo Unified Crew Hatch. ${ }^{17}$

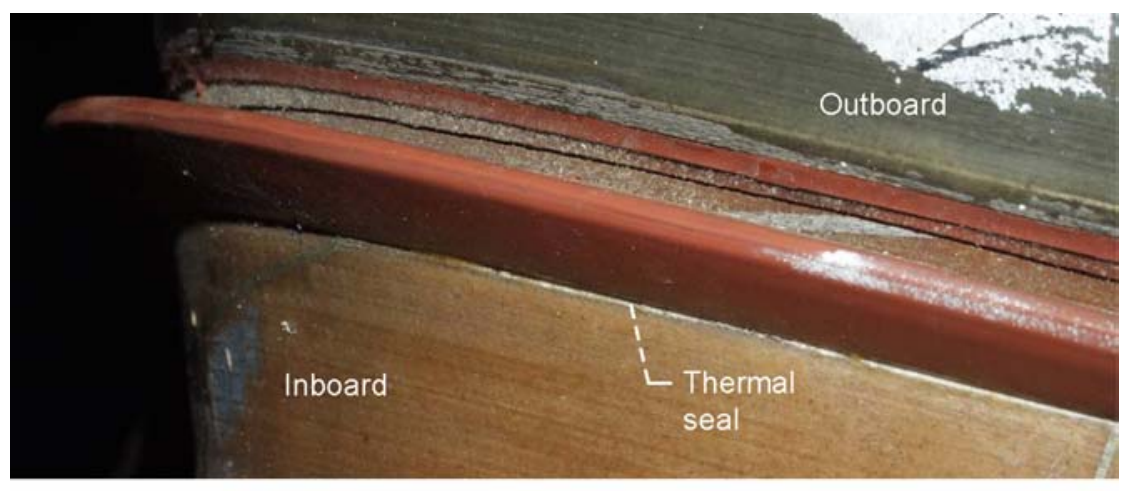

CD-06-82888-2a

Figure 20. Photograph of UCH hatch thermal seal on Apollo/Skylab 3 command module.

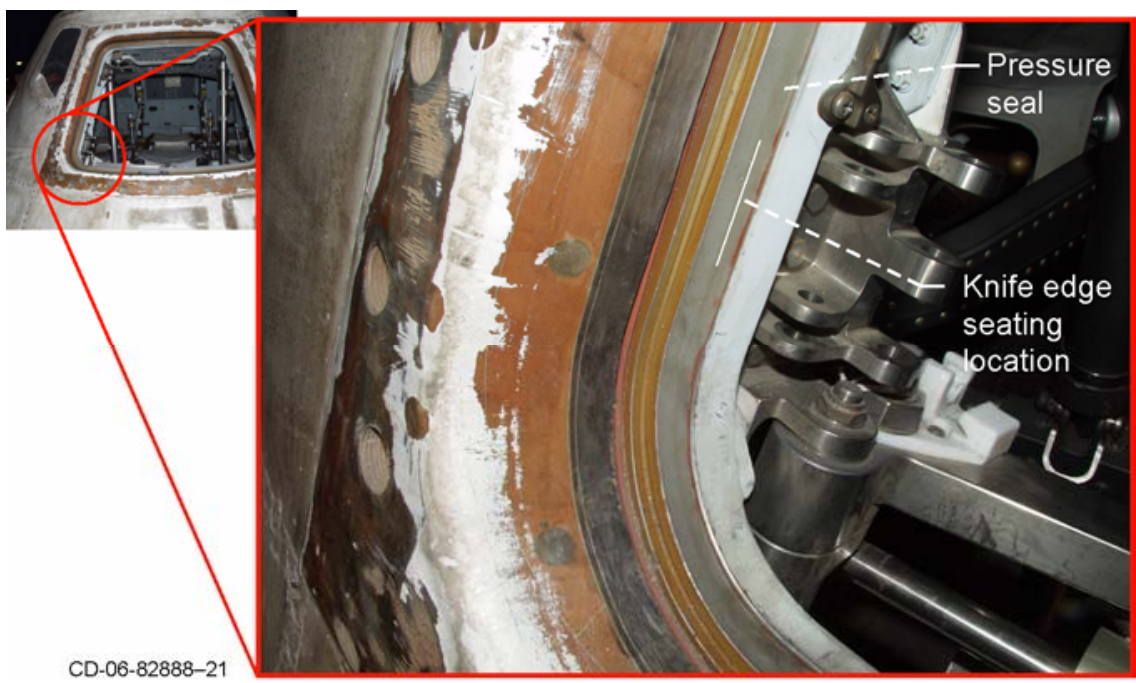

Figure 21. Photograph of hatch frame on the Apollo/Skylab 3 command module. A residual discoloration can be seen where the $\mathrm{UCH}$ knife edge engaged into the elastomer gasket. 


\section{Command Module Forward Tunnel and Docking Ring}

Figure 22 shows a schematic diagram of the forward tunnel assembly used to dock the command module to the lunar module. The docking ring was attached to the command module tunnel ring and served as a mounting structure for the latches, electrical connections, and probe assembly for docking with the lunar module. The docking assembly contained several seals: a pressure seal and a thermal seal on the forward tunnel hatch, a pressure seal at the junction between the command module tunnel ring and the docking ring, another pressure seal at the junction between the docking ring and the lunar module tunnel ring, and at least one pressure seal on the lunar module hatch door.

Figure 23 shows a diagram of the inboard side of the forward tunnel hatch which includes callouts to an outboard thermal seal and an inboard knife edge which constitutes part of a pressure seal. The thermal seal prevented ingestion of high enthalpy reentry gases into the gap around the hatch. Figure 24, a photograph of the stowed hatch taken during the Apollo 17 mission, shows a thermal seal O-ring formed from a high temperature elastomer material. The thermal seal was compressed against the forward tunnel wall near the location denoted with a number "7" in Fig. 25, a photograph of the forward tunnel in the Apollo/Skylab 3 command module. The thermal seal was not as large as that for the UCH because the thermal environment at the apex of the conical portion of the command module was minimal and did not impose a heavy thermal load onto the seal.

The forward tunnel hatch also contained a pressure seal similar to that on the UCH which was constituted by the knife edge denoted in Fig. 23 which embedded into an elastomer gasket attached circumferentially around the forward tunnel. The elastomer gasket can be seen in the photograph of the Apollo/Skylab 3 forward tunnel in Fig. 25. When the outboard side of the hatch was exposed to vacuum conditions (e.g., the command module was not docked to the lunar module), the pressure differential across the hatch served to provide positive engagement of the knife edge into the elastomer gasket and therefore improved the performance of the seal. The pressure equalization valve shown on the hatch in Fig. 23 allowed the docking ring tunnel to be pressurized after the command module had docked to the lunar module. Once the internal and external pressures had been equalized, the latches were disengaged and the hatch was removed and stowed inside the command module. ${ }^{19}$

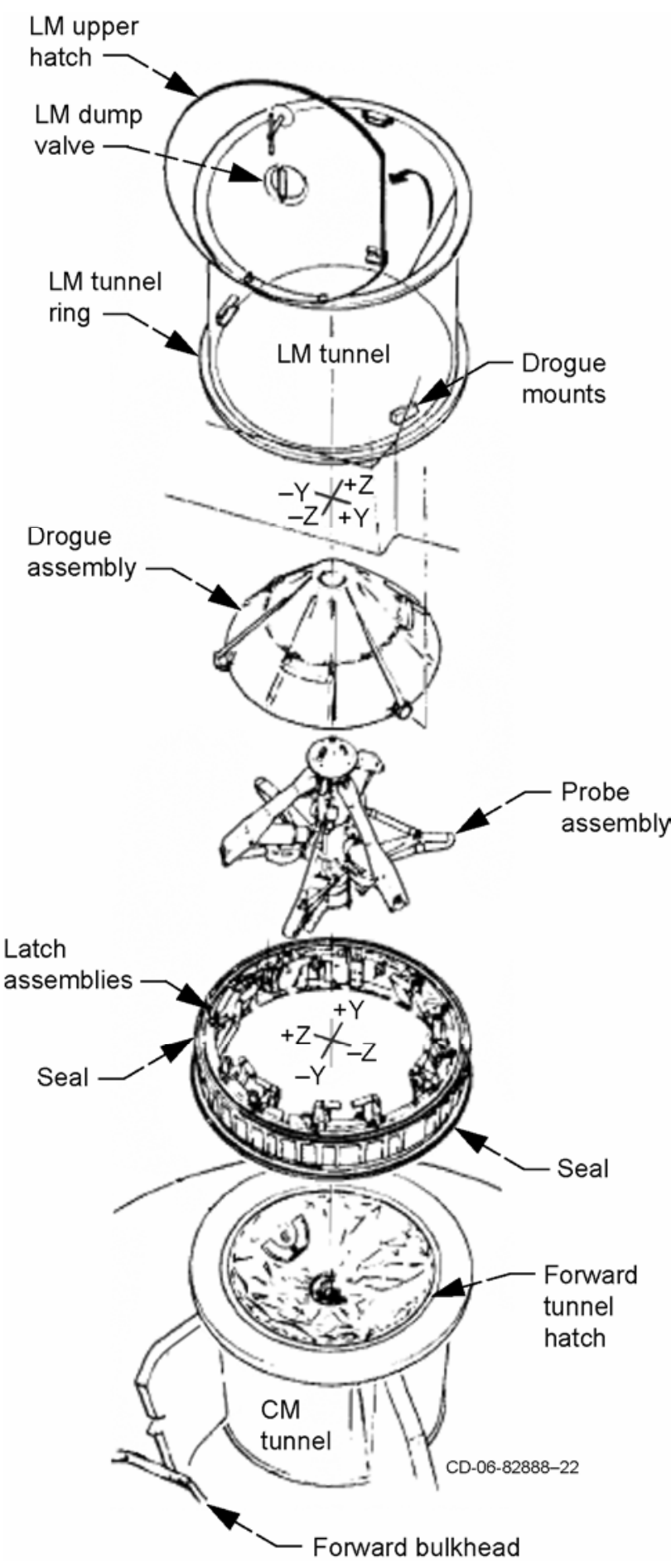

Figure 22. Apollo docking assembly. ${ }^{19}$ 


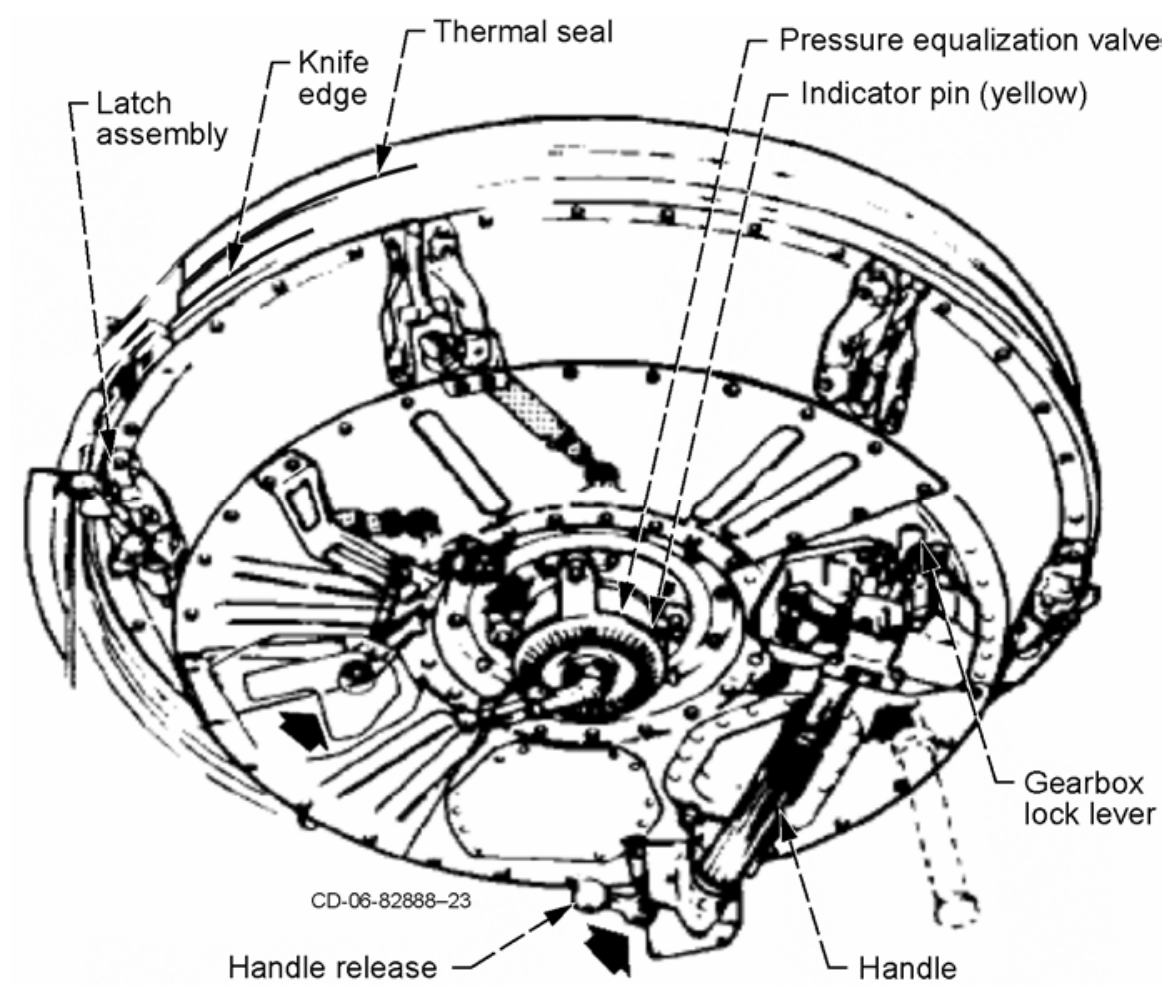

Figure 23. Drawing of the inboard side of the Apollo command module forward tunnel hatch. ${ }^{19}$

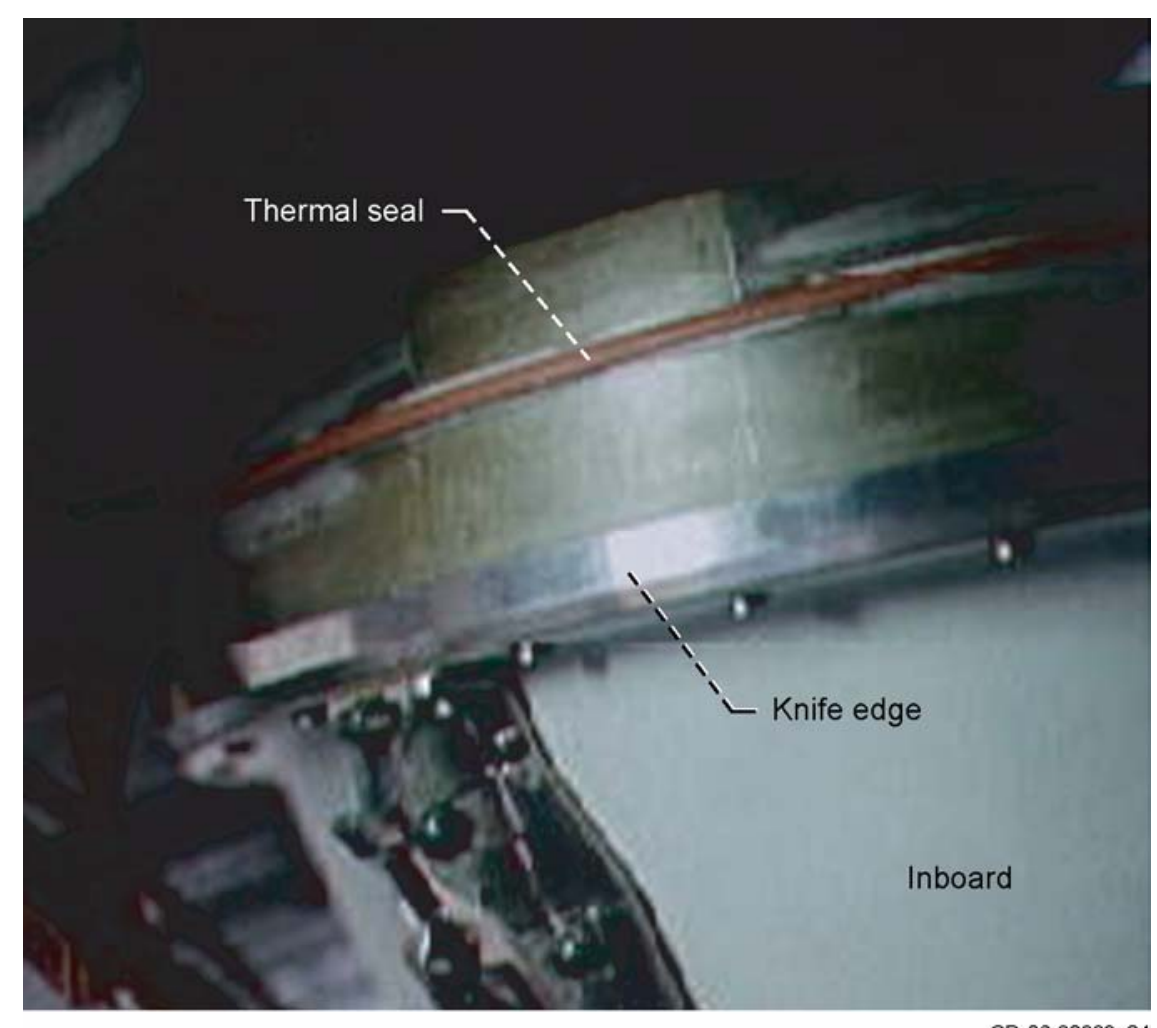

CD-06-82888-24

Figure 24. Photograph of stowed forward tunnel hatch from Apollo 17 (zoomed in from AS17-162-24054). 


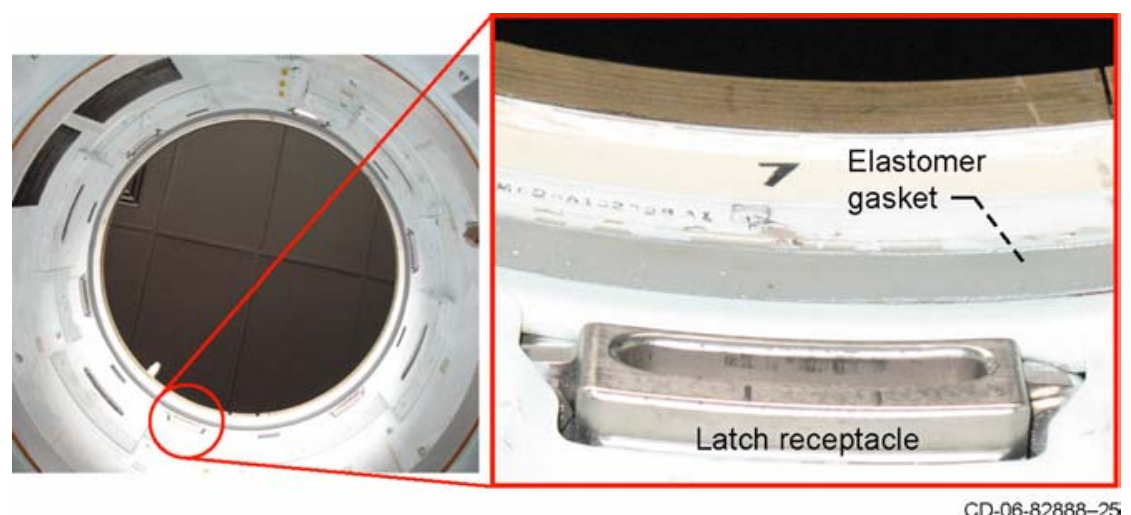

Figure 25. Photograph of forward tunnel and pressure seal on forward tunnel of Apollo/Skylab 3 command module.

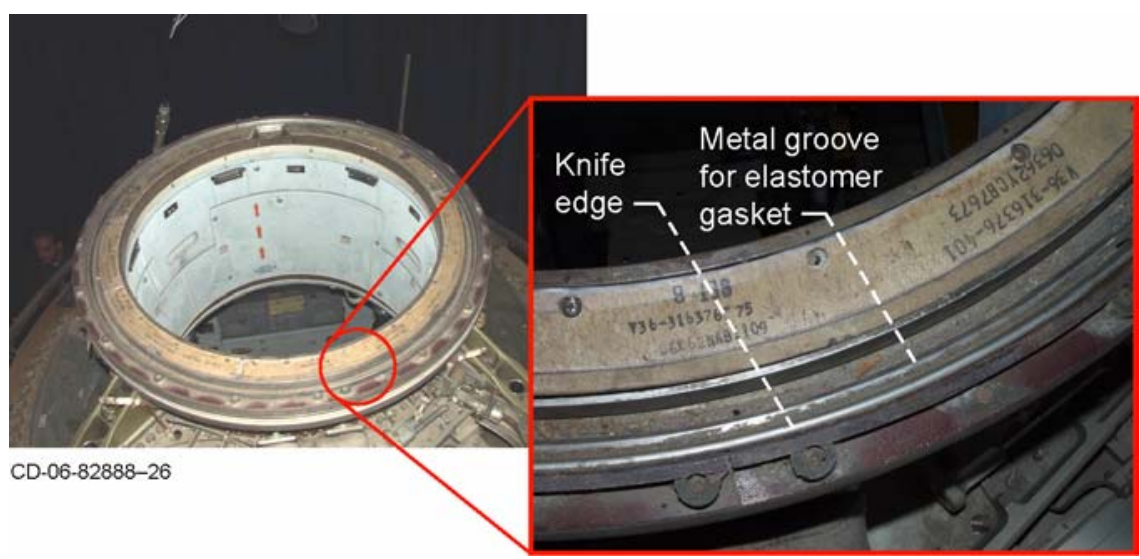

Figure 26. Apollo/Skylab 3 command module tunnel ring and metal groove for mounting elastomer pressure seal.

Two seals are indicated on the docking ring in Fig. 22. The first was located between the docking ring and the command module tunnel ring and the second was between the docking ring and the lunar module tunnel ring. The docking ring was jettisoned with the lunar module and therefore could not be examined to determine the nature of the seals. Based on the drawings and photographs of the docking ring and the adjoining command module tunnel ring, it may be inferred that the two docking ring seals were similar to the pressure seals used for the UCH and the forward tunnel hatch. The docking ring appears to have included a circumferential knife edge at each of its axial ends. The knife edge facing the command module embedded into an elastomer band installed around the outside perimeter of the command module forward tunnel. A photograph showing the top of the Apollo/Skylab 3 command module tunnel ring is shown in Fig. 26, where a circumferential groove presumably contained the elastomer pressure seal. Interestingly, a knife edge is shown outboard of the groove in Fig. 26 and may indicate that the junction between the command module tunnel ring and the docking ring contained two pressure seals, with each surface containing both an elastomer gasket and a knife edge.

\section{Command Module Windows}

The Apollo command module included five windows as shown in Fig. 27. The side and hatch windows were generally used for observation and photography while the rendezvous windows (windows 2 and 4) were oriented in the forward direction ( $+\mathrm{X}$ in the figure) and provided visual guidance for docking.

Figure 28 shows the construction of each of the three types of windows including the seals necessary to prevent both cabin atmosphere loss and reentry gas ingestion. The windows were made of two aluminosilicate glass inner pressure panes and a fused amorphous silica outer heat shield pane. Each of the inner window panes was coated on both sides with an antireflective coating to reduce glare. The outer pane was coated on the outside with a magnesium-fluoride coating and on the inside with a blue-red coating to block both infrared and ultraviolet solar radiation. $^{20}$ 

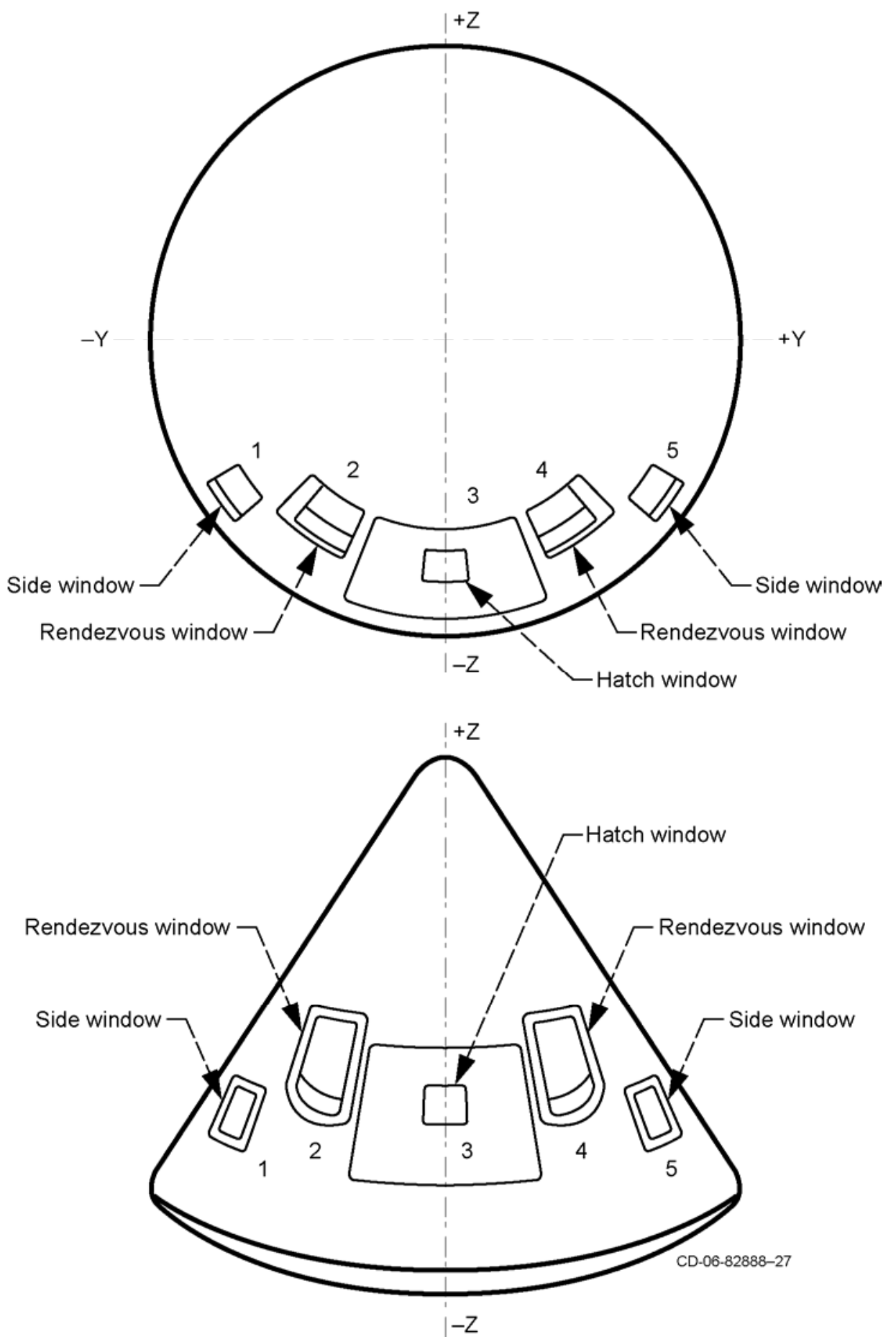

Figure 27. Window locations on the Apollo command module. ${ }^{21}$ 

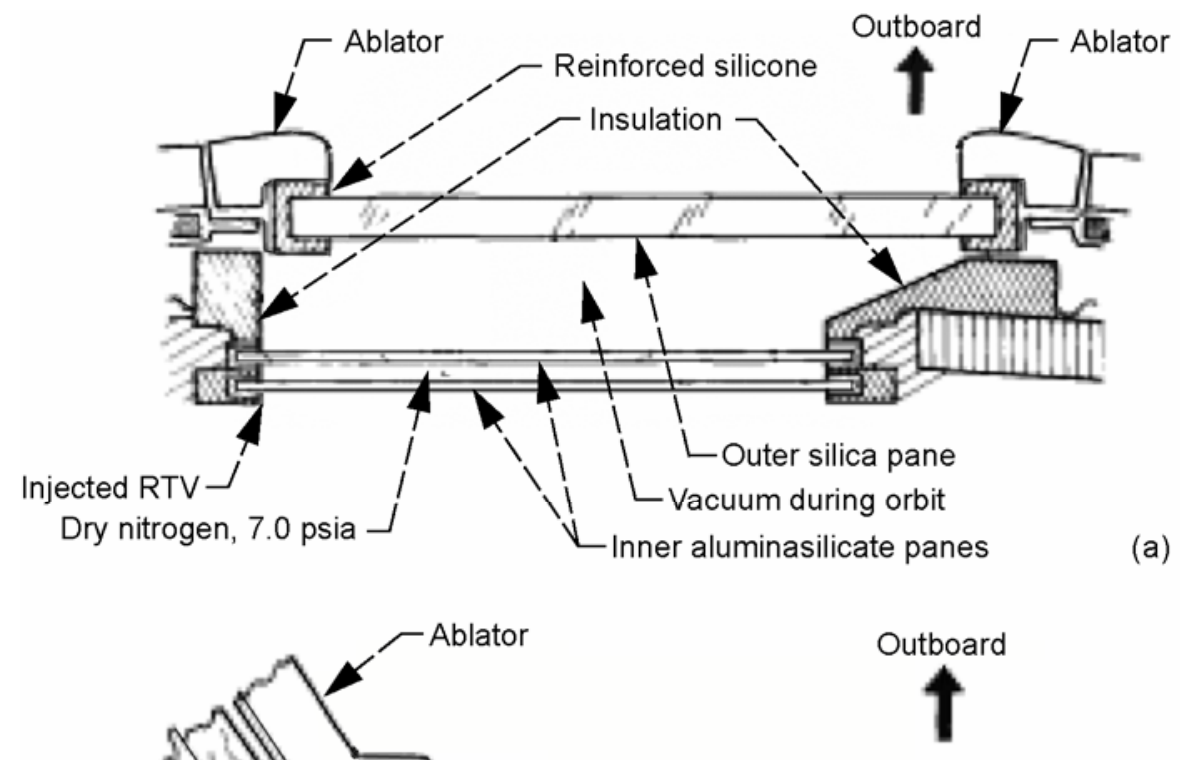

(a)
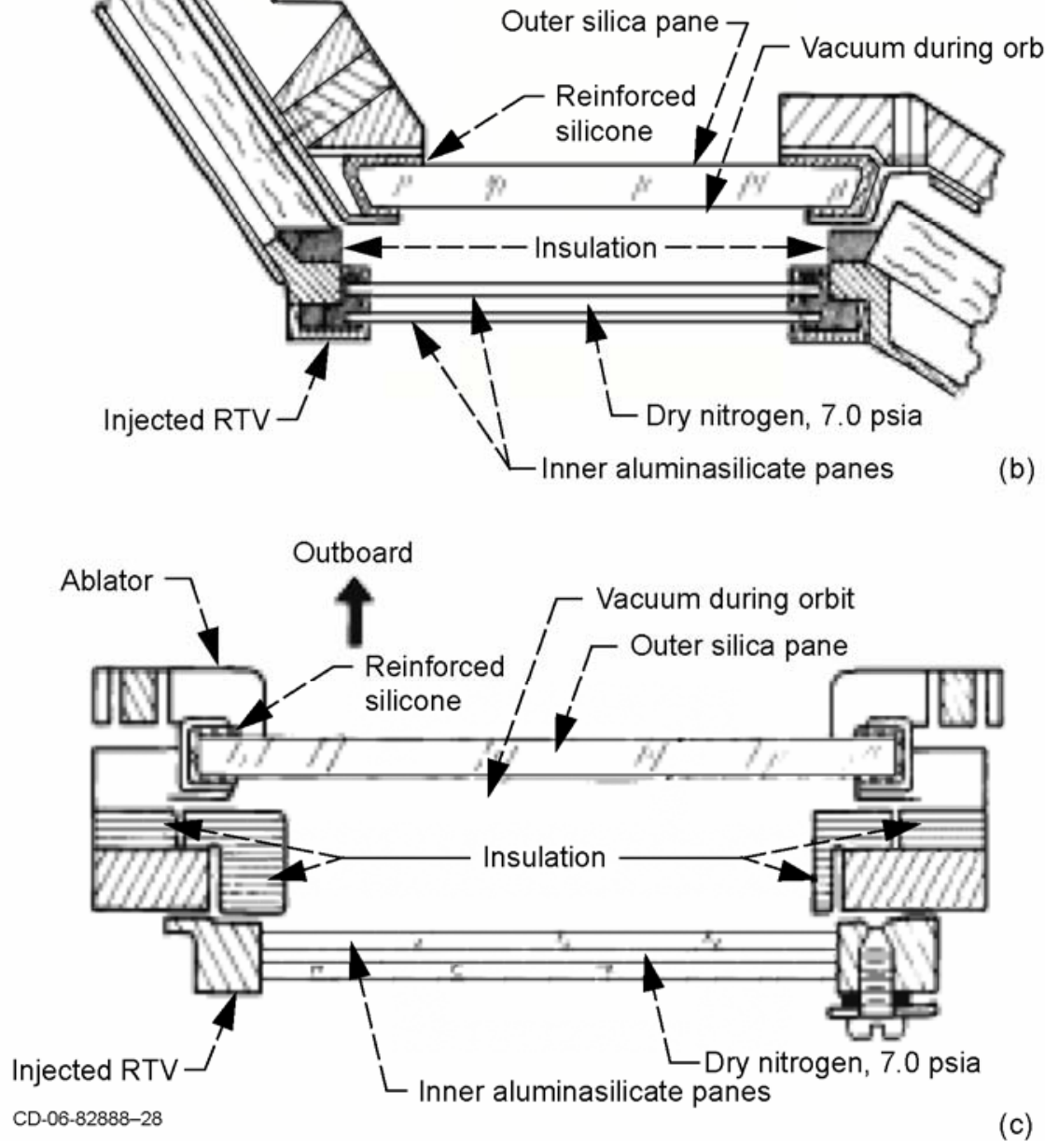

Figure 28. Apollo command module windows: ${ }^{20}$ (a) side windows 1 and 5, (b) rendezvous windows 2 and 4 , (c) hatch window 3. 


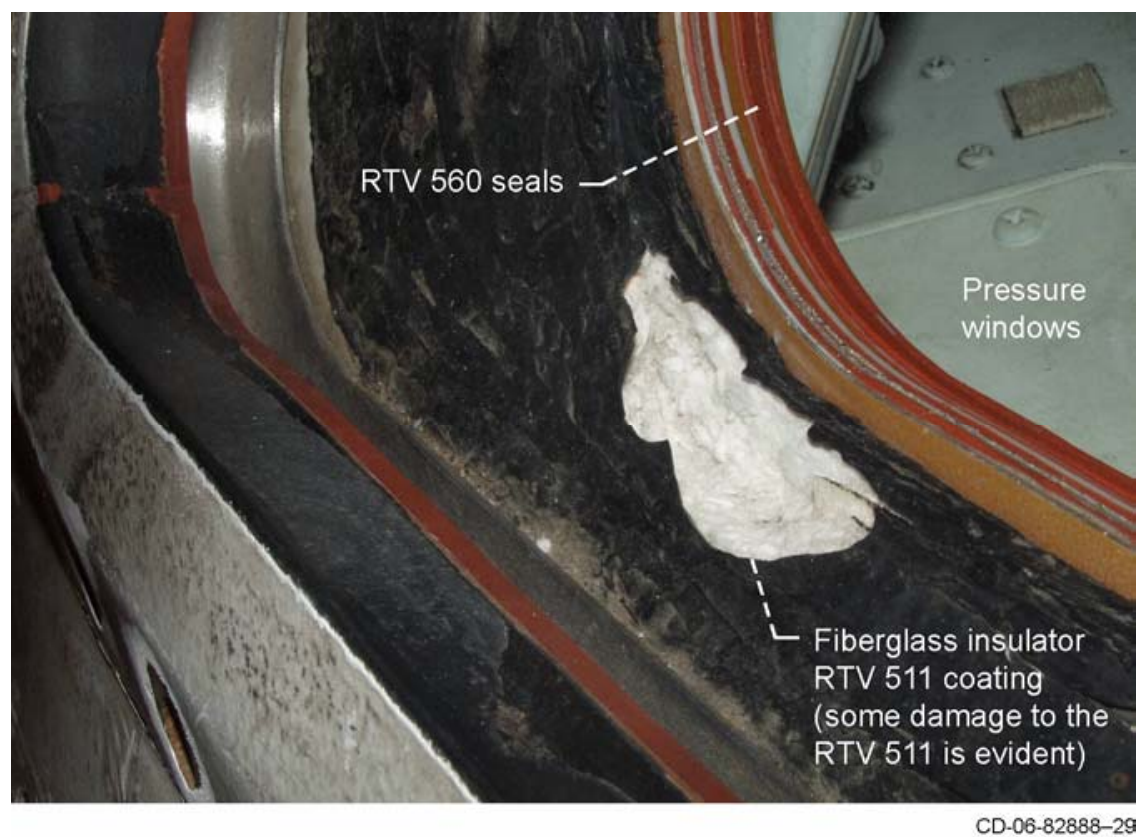

Figure 29. Photograph of window 1 on Apollo/Skylab 3 vehicle. The outer
heat shield silica pane is not present.

The seal around the pressure windows was formed by injecting RTV 560 around the perimeters of the two inner panes and allowing the silicone to cure in place. ${ }^{20}$ The RTV was held in place while it was curing by heat molded silicone elastomer dams which were installed around the perimeters of the windows. ${ }^{21}$ Once the silicone had cured, the cavity between the inner windows was evacuated and backfilled with 7.0 psia nitrogen gas. A multilayer silicone resin-impregnated fiberglass insulator with an RTV 511 coating was bonded with RTV $511^{21}$ to the outboard perimeter of the inner window panes to minimize heat conduction to the inner windows during reentry. The outer heat shield window was attached using a glass cloth reinforced heat-molded silicone rubber which was bonded in place with RTV 560. Window 1 and its associated seals and insulation layer from Apollo/Skylab 3 are shown in Fig. 29. A portion of the outer RTV 511 coating is removed from the insulator, so the exposed fiberglass insulation can be seen. Also, the outer heat shield silica pane is missing from the capsule and may have been removed after recovery of the vehicle.

\section{Sextant and Telescope}

An assembly consisting of a sextant and a scanning telescope, shown in Fig. 30, was installed on the windward surface of the crew compartment heat shield of the Apollo command module. The inclusion of the sextant represented a significant sealing challenge. The sextant penetrated both the pressure hull and the crew compartment heat shield on the windward side of the vehicle. The sextant was free to rotate and was capable of some movement along the axis of rotation. The sealing challenge was overcome using the seal design shown in the schematic diagram in Fig. 31. The flexible thermal seal prevented the flow of high enthalpy reentry gas into the cavity between the cabin and the TPS wall (Fig. 31) while allowing movement of the sextant TPS with respect to the cabin. ${ }^{5}$ Additionally, the slip ring seal around the sextant prevented high enthalpy gas flow along the outside circumference of the sextant and into the cabin. The slip ring seal also minimized habitable atmospheric losses from the crew cabin along the outer circumference of the rotating optics. 


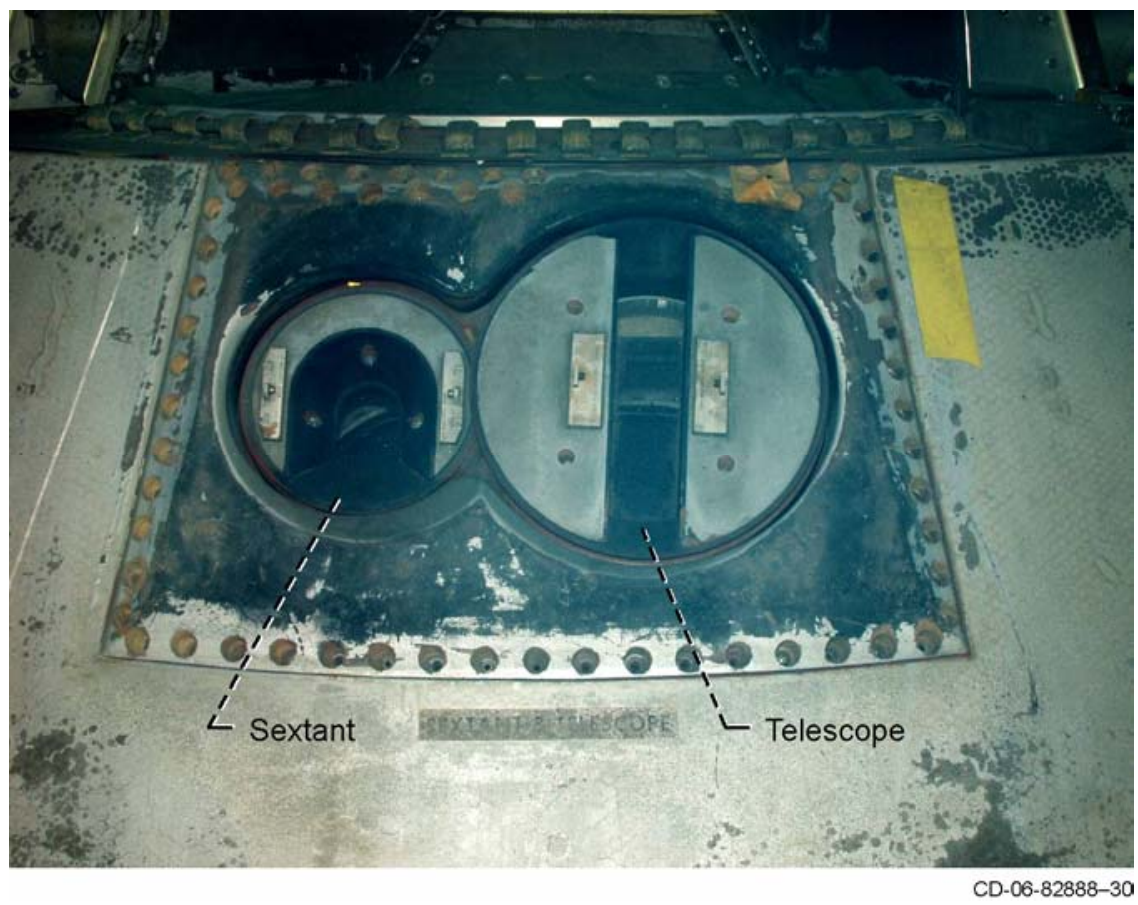

Figure 30. Sextant and telescope assembly on the Apollo/Skylab 3 command module.

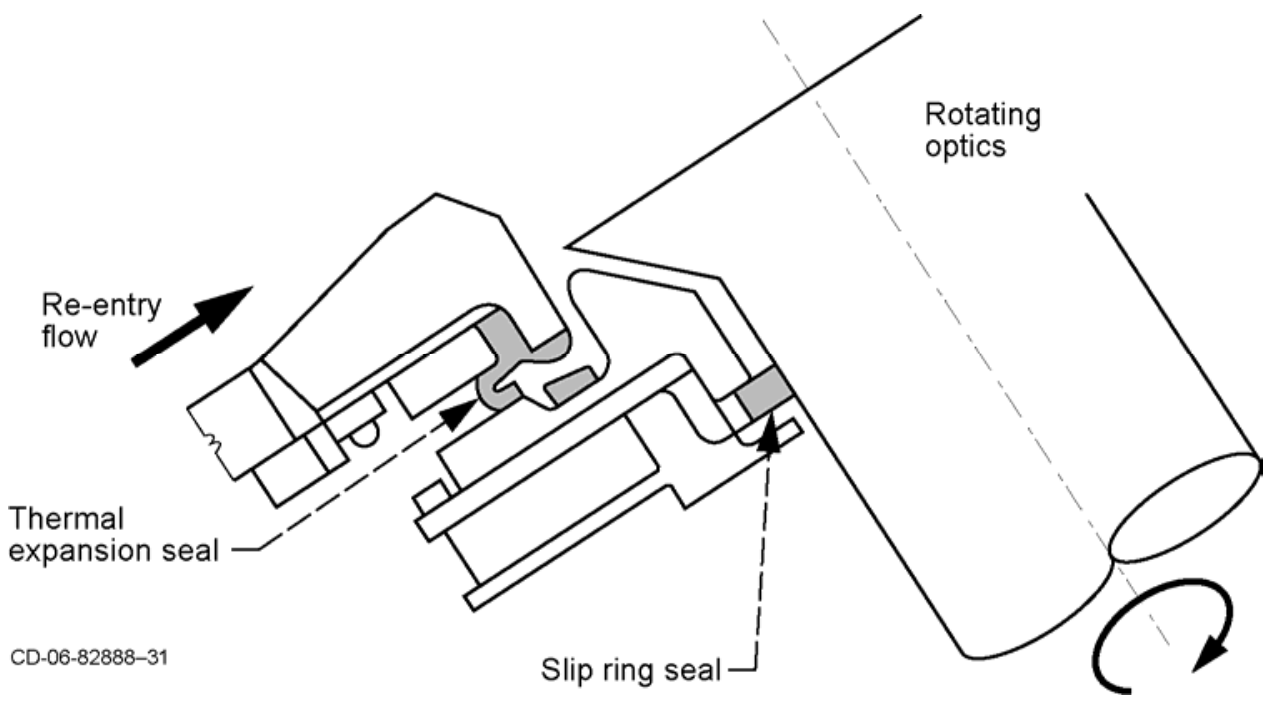

Figure 31. Sectional view of Apollo command module sextant port. ${ }^{5}$

\section{Conclusions}

The Apollo command module incorporated a wide variety of pressure and thermal seals to prevent the loss of crew cabin atmosphere and to prevent ingestion of high enthalpy reentry gases into gaps in the thermal protection system. Bolted and riveted joints used to assemble the pressure hull as well as the command module windows were sealed with RTV. The two access hatches were sealed with metal knife edges embedded into elastomer gaskets and also incorporated thermal seals to prevent ingestion of high enthalpy reentry gases. Thermal seals throughout the vehicle, including boundaries between different heat shield components, access panels, and RCS motors were composed primarily of high temperature RTV. The highest temperature regions of the command module, including 
both the aft heat shield and aft heat shield-to-crew compartment heat shield interface gap, incorporated silicone seals and gaskets. Inspections of these seals on the Apollo/Skylab 3 capsule revealed evidence of ablation from their outer surfaces. Thermal seals on the crew compartment heat shield and forward heat shield were exposed to lower temperatures, and visual inspections of the lower temperature seals on the Apollo/Skylab 3 vehicle did not reveal significant evidence of ablation.

\section{References}

1. "NASA's Exploration Systems Architecture Study Final Report,” NASA/TM-2005-214062, 2005.

2. "Apollo - A Program Review," Society of Automotive Engineers, Inc., SP-257, 1964.

3. Sullivan, Scott P. "Virtual Apollo." Collector's Guide Publishing Inc., Ontario, Canada, 2002.

4. Lee, D. B. and Goodrich, W. D., "The Aerothermodynamic Environment of the Apollo Command Module During Superorbital Entry," NASA TN D-6792, 1972.

5. Erb, R. B., Greenshields, D. H., Chauvin, L. T. and Pavlosky, J. E., “Apollo Thermal-Protection System Development," Journal of Spacecraft and Rockets, Vol. 7, No. 6, 1970, pp. 727-734.

6. Lee, D. B., Bertin, J. J. and Goodrich, W. D., "Heat-Transfer Rate and Pressure Measurements Obtained During Apollo Orbital Entries," NASA TN D-6028, 1970.

7. Lee, D. B., “Apollo Experience Report - Aerothermodynamics Evaluation,” NASA TN D-6843, 1972.

8. Wright, M. J., Prabhu, D. K. and Martinez, E. R., "Analysis of Apollo Command Module Afterbody Heating Part I: AS202," Journal of Thermophysics and Heat Transfer, Vol. 20, No. 1, 2006, pp. 16-30.

9. Pavlosky, J. E. and St. Leger, L. G., “Apollo Experience Report - Thermal Protection Subsystem,” NASA TN D-7564, 1974.

${ }^{10 .}$ Coplan, B. V. and King, R. W., "Applying the Ablative Heat Shield to the Apollo Spacecraft," 4th Space Congress: The Challenge of the 1970s, vol. 15, 1967, pp. 34-44.

${ }^{11 .}$ Falbo, M. J. and Robinson, R. L., "Apollo Experience Report - Spacecraft Pyrotechnic Systems," NASA TN D-7141, 1973.

12. Personal communication with Conley Thatcher, Boeing Corporation, January 10, 2006.

13. Taeuber, R. J. and Weary, D. P., "Apollo Experience Report - Command and Service Module Reaction Control Systems," NASA TN D-7151, 1973.

14.Vaughan, C. A., “Apollo Reaction Control Systems," Propulsion Joint Specialist Conference, Cleveland, OH, June 10-14, 1968, AIAA Paper 68-566.

${ }^{15}$ Charhut, D. E., Byke, R. M. and McClelland, C. M., "Design of Space Stations for Low Atmospheric Leakage," Journal of Spacecraft and Rockets, Vol. 9, No. 1, 1972, pp. 26-32. 1968.

${ }^{16}$ Kimzey, J. H., "Flammable and Toxic Materials in the Oxygen Atmosphere of Manned Spacecraft," NASA TN D-3415,

${ }^{17}$ Walkover, L. J., Hart, R. J. and Zosky, E. W., "The Apollo Command Module Side Access Hatch System," North American Rockwell Corporation, JPL Technical Memorandum 33-425.

18.“Apollo Hatch Redesign: A Matter of Urgency,” Historic Space Systems Info Sheet, Issue 2, 1996.

19. Langley, R. D., “Apollo Experience Report - The Docking System,” NASA TN D-6854, 1972.

${ }^{20}$ Pigg, O. E. and Weiss, S. P., "Apollo Experience Report - Spacecraft Structural Windows," NASA TN D-7439, 1973.

${ }^{21}$ Leger, L. J. and Bricker, R. W., “Apollo Experience Report - Window Contamination,” NASA TN D-6721, 1972. 


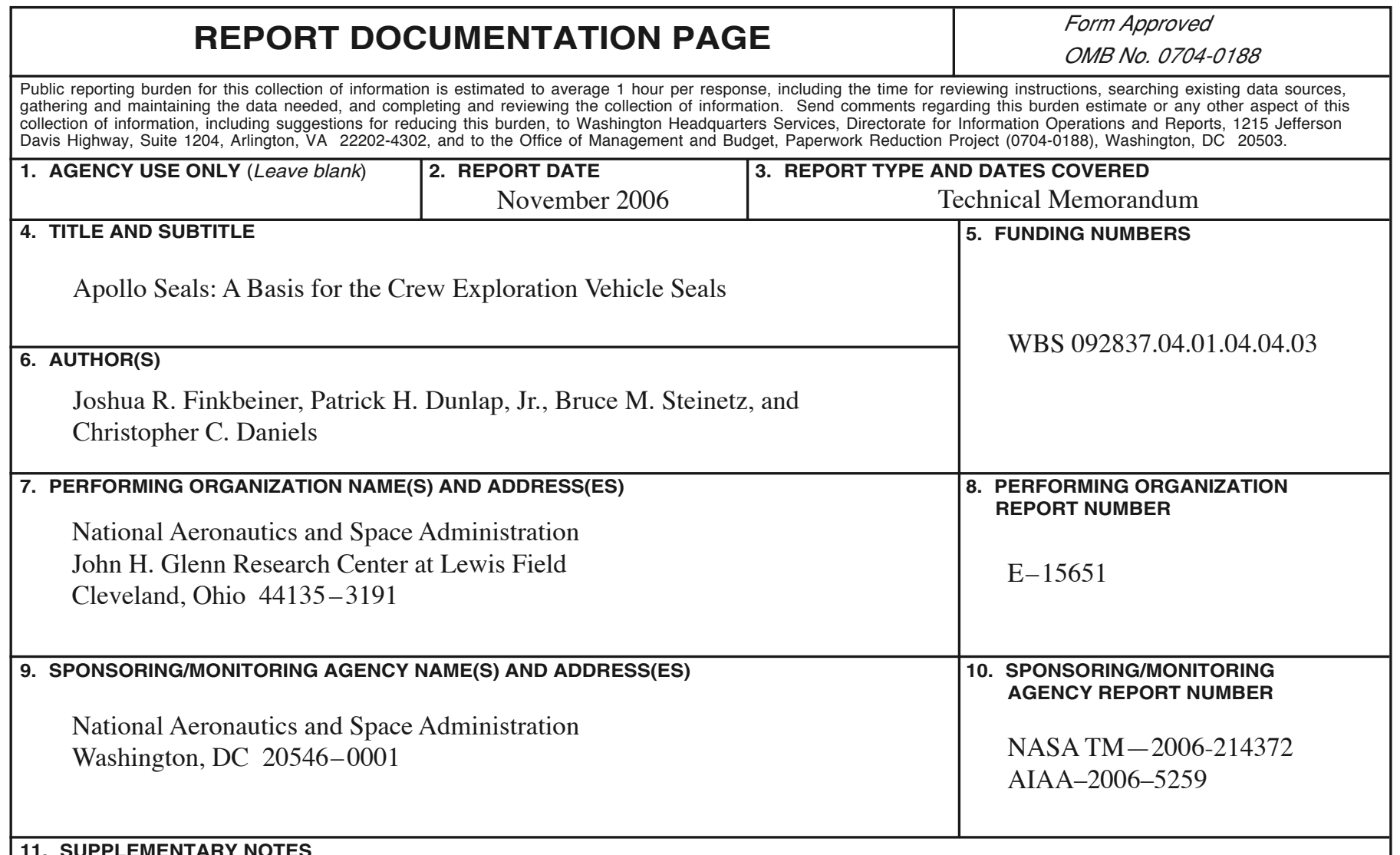

\section{SUPPLEMENTARY NOTES}

Prepared for the 42nd Joint Propulsion Conference and Exhibit cosponsored by the AIAA, ASME, SAE, and ASEE, Sacramento, California, July 9-12, 2006. Joshua R. Finkbeiner, Patrick H. Dunlap, Jr., and Bruce M. Steinetz, NASA Glenn Research Center; and Christopher C. Daniels, University of Akron, 302 Buchtel Mall, Akron, Ohio 44325.

Responsible person, Joshua R. Finkbeiner, organization code RXM, 216-433-6080.

12a. DISTRIBUTION/AVAILABILITY STATEMENT

12b. DISTRIBUTION CODE

Unclassified - Unlimited

Subject Categories: 37 and 18

Available electronically at http://gltrs.grc.nasa.gov

This publication is available from the NASA Center for AeroSpace Information, 301-621-0390.

13. ABSTRACT (Maximum 200 words)

The National Aeronautics and Space Administration is currently designing the Crew Exploration Vehicle (CEV) as a replacement for the Space Shuttle for manned missions to the International Space Station, as a command module for returning astronauts to the moon, and as an earth reentry vehicle for the final leg of manned missions to the moon and Mars. The CEV resembles a scaled-up version of the heritage Apollo vehicle; however, the CEV seal requirements are different than those from Apollo because of its different mission requirements. A review is presented of some of the seals used on the Apollo spacecraft for the gap between the heat shield and backshell and for penetrations through the heat shield, docking hatches, windows, and the capsule pressure hull.

\begin{tabular}{|c|c|c|}
\hline \multicolumn{3}{|l|}{ 14. SUBJECT TERMS } \\
\hline \multicolumn{3}{|c|}{$\begin{array}{l}\text { Sealing; Seals (stoppers); Spacecraft structures; Leakage reduction; Reentry shielding; Apollo } \\
\text { spacecraft; Crew Exploration Vehicle; Spacecraft docking; Materials; Thermal protection systems }\end{array}$} \\
\hline $\begin{array}{l}\text { 17. SECURITY CLASSIFICATION } \\
\text { OF REPORT }\end{array}$ & $\begin{array}{l}\text { 18. SECURITY CLASSIFICATION } \\
\text { OF THIS PAGE }\end{array}$ & $\begin{array}{l}\text { 19. SECURITY CLASSIFICATION } \\
\text { OF ABSTRACT }\end{array}$ \\
\hline Unclassified & Unclassified & Unclassified \\
\hline
\end{tabular}

15. NUMBER OF PAGES

29

16. PRICE CODE

20. LIMITATION OF ABSTRACT

Standard Form 298 (Rev. 2-89)

Prescribed by ANSI Std. Z39-18 298-102 

